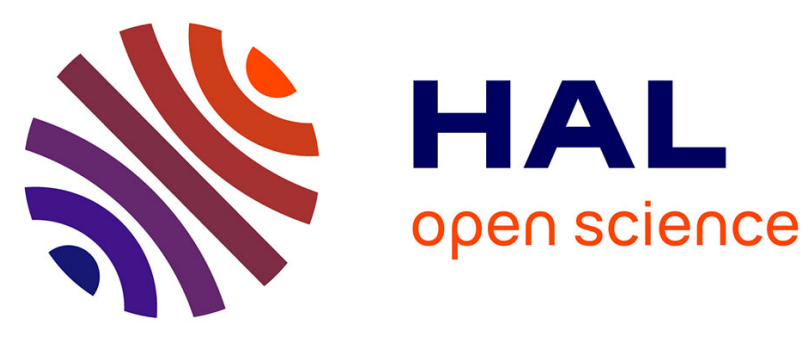

\title{
LIM homeobox-2 suppresses hallmarks of adult and pediatric liver cancers by inactivating MAPK/ERK and Wnt/beta-catenin pathways
}

Nicola Mosca, Fatma Zohra Khoubai, Sandrine Fedou, Juan Carrillo-Reixach, Stefano Caruso, Alvaro del Rio-Alvarez, Emeric Dubois, Christophe Avignon, Nathalie Dugot-Senan, Catherine Guettier, et al.

\section{To cite this version:}

Nicola Mosca, Fatma Zohra Khoubai, Sandrine Fedou, Juan Carrillo-Reixach, Stefano Caruso, et al.. LIM homeobox-2 suppresses hallmarks of adult and pediatric liver cancers by inactivating MAPK/ERK and Wnt/beta-catenin pathways. Liver Cancer, 2021, Online ahead of print. 10.1159/000521595 . inserm-03556999

\section{HAL Id: inserm-03556999 https://www.hal.inserm.fr/inserm-03556999}

Submitted on 4 Feb 2022

HAL is a multi-disciplinary open access archive for the deposit and dissemination of scientific research documents, whether they are published or not. The documents may come from teaching and research institutions in France or abroad, or from public or private research centers.
L'archive ouverte pluridisciplinaire HAL, est destinée au dépôt et à la diffusion de documents scientifiques de niveau recherche, publiés ou non, émanant des établissements d'enseignement et de recherche français ou étrangers, des laboratoires publics ou privés. 


\title{
LIM Homeobox-2 Suppresses Hallmarks of Adult and Pediatric Liver Cancers by Inactivating MAPK/ ERK and Wnt/Beta-Catenin Pathways
}

\author{
Nicola Mosca ${ }^{a}$ Fatma Zohra Khoubai $^{\mathrm{a}}$ Sandrine Fedou ${ }^{\mathrm{a}, \mathrm{b}}$ \\ Juan Carrillo-Reixach ${ }^{c, d}$ Stefano Caruso ${ }^{e}$ Alvaro Del Rio-Alvarez ${ }^{c}$ \\ Emeric Dubois ${ }^{f}$ Christophe Avignon ${ }^{g}$ Nathalie Dugot-Senant ${ }^{\mathrm{h}}$ \\ Catherine Guettier ${ }^{9}$ Charlotte Mussini ${ }^{9}$ Jessica Zucman-Rossie, i \\ Carolina Armengol ${ }^{c, d}$ Pierre Thiébaud ${ }^{a, b}$ Philippe Veschambre ${ }^{a}$ \\ Christophe François Grosset ${ }^{a}$
}

${ }^{a}$ MIRCADE Team, Univ. Bordeaux, Inserm, BMGIC, Biotherapy of Genetic Diseases, Inflammatory Disorders and Cancers, U1035, Bordeaux, France; ' XenoFish, Univ. Bordeaux, Inserm, BMGIC, Biotherapy of Genetic Diseases, Inflammatory Disorders and Cancers, U1035, Bordeaux, France; ${ }^{C}$ Childhood Liver Oncology Group, Germans Trias i Pujol Research Institute (IGTP), Program for Predictive and Personalized Medicine of Cancer (PMPPC), Badalona, Spain; ${ }^{\mathrm{d} C I B E R}$, Hepatic and Digestive Diseases, Barcelona, Spain; ${ }^{e}$ Centre de Recherche des Cordeliers, Sorbonne Université, Université de Paris, INSERM, Functional Genomics of Solid Tumors Laboratory, Paris, France; ${ }^{f}$ Montpellier GenomiX, University of Montpellier, CNRS, INSERM, Montpellier, France; ' ${ }^{D}$ epartment of Pathology, Bicêtre University Hospital, University of Paris-Saclay, Assistance Publique-Hôpitaux de Paris, Le Kremlin-Bicêtre, France; 'Plateforme d'histopathologie Inserm, US 005 - UMS3427 - TBMCore, Bordeaux, France; 'Hôpital Européen Georges Pompidou, Assistance Publique-Hôpitaux de Paris, Paris, France

\section{Keywords}

Hepatocellular carcinoma · Hepatoblastoma - LHX2 - Wnt pathway · MAPK/ERK pathway

\footnotetext{
Abstract

Introduction: Hepatocellular carcinoma and hepatoblastoma are two liver cancers characterized by gene deregulations, chromosomal rearrangements, and mutations in Wnt/betacatenin (Wnt) pathway-related genes. LHX2, a transcriptional factor member of the LIM homeobox gene family, has important functions in embryogenesis and liver development. LHX2 is oncogenic in many solid tumors and leukemia, but its role in liver cancer is unknown. Methods: We analyzed the expression of $L H X 2$ in hepatocellular carcinoma and hepatoblastoma sam-
}

karger@karger.com www.karger.com/lic

Karger!"

GOPEN ACCESS
(C) 2021 The Author(s)

Published by S. Karger AG, Basel

This is an Open Access article licensed under the Creative Commons Attribution-NonCommercial-4.0 International License (CC BY-NC) (http://www.karger.com/Services/OpenAccessLicense), applicable to the online version of the article only. Usage and distribution for commercial purposes requires written permission. ples using various transcriptomic datasets and biological samples. The role of LHX2 was studied using lentiviral transduction, in vitro cell-based assays (growth, migration, senescence, and apoptosis), molecular approaches (phosphokinase arrays and RNA-seq), bioinformatics, and two in vivo models in chicken and Xenopus embryos. Results: We found a strong connection between LHX2 downregulation and Wnt activation in these two liver cancers. In hepatoblastoma, LHX2 downregulation correlated with multiple poor outcome parameters including higher patient age, intermediate- and high-risk tumors, and low patient survival. Forced expression of LHX2 reduced the proliferation, migration, and survival of liver cancer cells in vitro through the inactivation of MAPK/ERK and Wnt signals. In vivo, LHX2 impeded the development of tumors in chick embryos and repressed the Wnt pathway in Xenopus embryos. RNA-se- 
quencing data and bioinformatic analyses confirmed the deregulation of many biological functions and molecular processes associated with cell migration, cell survival, and liver carcinogenesis in LHX2-expressing hepatoma cells. At a mechanistic level, LHX2 mediated the disassembling of betacatenin/T-cell factor 4 complex and induced expression of multiple inhibitors of Wnt (e.g., TLE/Groucho) and MAPK/ERK (e.g., DUSPs) pathways. Conclusion: Collectively, our findings demonstrate a tumor suppressive function of LHX2 in adult and pediatric liver cancers.

C 2021 The Author(s)

Published by S. Karger AG, Basel

\section{Introduction}

Hepatocellular carcinoma (HCC) and hepatoblastoma (HB) are malignant tumors originating from hepatocytes. While $80-90 \%$ of HCCs arise from a chronically diseased liver with viral, metabolic, or toxin etiologies [1], HBs develop on a healthy liver and some are associated with genetic syndromes such as familial adenomatous polyposis coli and Beckwith-Wiedemann syndromes [2]. HCC and HB share common molecular dysfunctions exemplified by activating mutations in the CTNNB1/beta-catenin gene or, less frequently, by inactivating mutations in AXIN1 or APC genes, which all lead to an aberrant activation of the Wnt signal [1-3]. While HCC is generally associated with deregulation in mitogen-activated protein kinase/extracellular signal-regulated kinase (MAPK/ERK) signaling [1, 4], classical fetal and embryonal HB does not carry TERT promoter mutations $[3,5]$. Both cancers are classified into two major subgroups based on the low or high proliferative capacity of the tumoral hepatic cells and are then stratified using transcriptional or genotype-phenotype approaches [6-11].
Other common features of HBs and HCCs include deregulations in chromatin modifiers, ubiquitin pathways, molecular signaling, and transcriptional regulators $[3,6,7,9]$.

The LIM homeobox genes form a family of 12 homeobox genes encoding proteins composed of two LIM domains located at the N-terminus and one homeodomain located at the C-terminus, which allow protein-protein interactions and DNA binding in target genes, respectively [12]. LIM homeobox proteins are nuclear transcription cofactors which interact with a myriad of transcriptional regulators (most belonging to the homeobox families) and control the expression of multiple genes and cellular functions [12]. Besides their key physiologic role in embryonic development, LIM homeobox genes are strongly associated with carcinogenesis. For instance, recent reviews pointed to a tumor suppressive role of LHX6 and LXM1A in many cancers with their decreased expression in malignant cells due to hypermethylation-mediated epigenetic silencing $[13,14]$. In contrast, current data support a broad oncogenic role of LHX2 in many cancers including chronic myeloid leukemia, pancreatic ductal carcinoma, breast cancer, nasopharyngeal carcinoma, and non-small cell lung cancer [12, 15-19]. The LHX2 gene is hypermethylated in breast cancer, lung cancer, and non-Hodgkin's lymphomas [12, 20]. In breast cancer, this hypermethylation occurs in intron 3 of the LHX2 gene and may promote the expression of LHX2 [20]. In a whole animal, LHX2 is required for normal development of the eyes, cerebral cortex, forebrain, and erythropoiesis and is involved in late stages of liver formation [21,22]. In the liver, LHX2 is expressed in hepatic stellate cells (HSC) of adult mice, and $\mathrm{Lhx} 2^{-/-}$mice display an increased expression and a higher accumulation of extracellular matrix proteins leading to liver fibrosis due to an uncontrolled activation of HSC [23]. Moreover, the expres-

Table 1. Biological samples and number of patients with an LHX2 expression level below the median of nontumoral livers

\begin{tabular}{|c|c|c|c|c|c|}
\hline Description & Source & Identifier & Samples, $n$ & $\begin{array}{l}\text { Patients with } \mathrm{LHX} 2< \\
\text { median NTL, } n(\%)\end{array}$ & Ref. \\
\hline Hepatocellular carcinomas & GEO & GSE45436 & 134 (39 NTL, 95 T) & $77(81)$ & 31 \\
\hline Hepatocellular carcinomas & & & $61(5 \mathrm{NTL}, 56 \mathrm{~T})$ & $52(93)$ & 9 \\
\hline Hepatocellular carcinomas & LICA-FR & & 203 (3 NTL, 200 T) & $190(95)$ & 29 \\
\hline Hepatocellular carcinomas & TCGA-LIHC & & $314 \mathrm{~T}$ & - & \\
\hline Hepatoblastomas & GEO & GSE132219/GSE133039 & 66 (32 NTL, 32 T, 2R) & $20(62.5)$ & 11 \\
\hline Hepatoblastomas & GEO & GSE75271 & $55(5 \mathrm{NTL}, 50 \mathrm{~T})$ & $40(80)$ & 32 \\
\hline Hepatoblastomas & GEO & GSE81928 & 32 (3 NTL, 29 T) & $27(93)$ & 33 \\
\hline Hepatoblastomas and cell lines & GEO & GSE104766 & $40(20 \mathrm{NTL}, 20 \mathrm{~T})$ & $18(90)$ & 7 \\
\hline Hepatoblastomas and cell lines & GEO & GSE131329 & 67 (14 NTL, 53 T) & $40(75)$ & 34 \\
\hline
\end{tabular}

GEO, Gene Expression Omnibus; NTL, nontumoral livers; T, tumors; R, recurrence. 

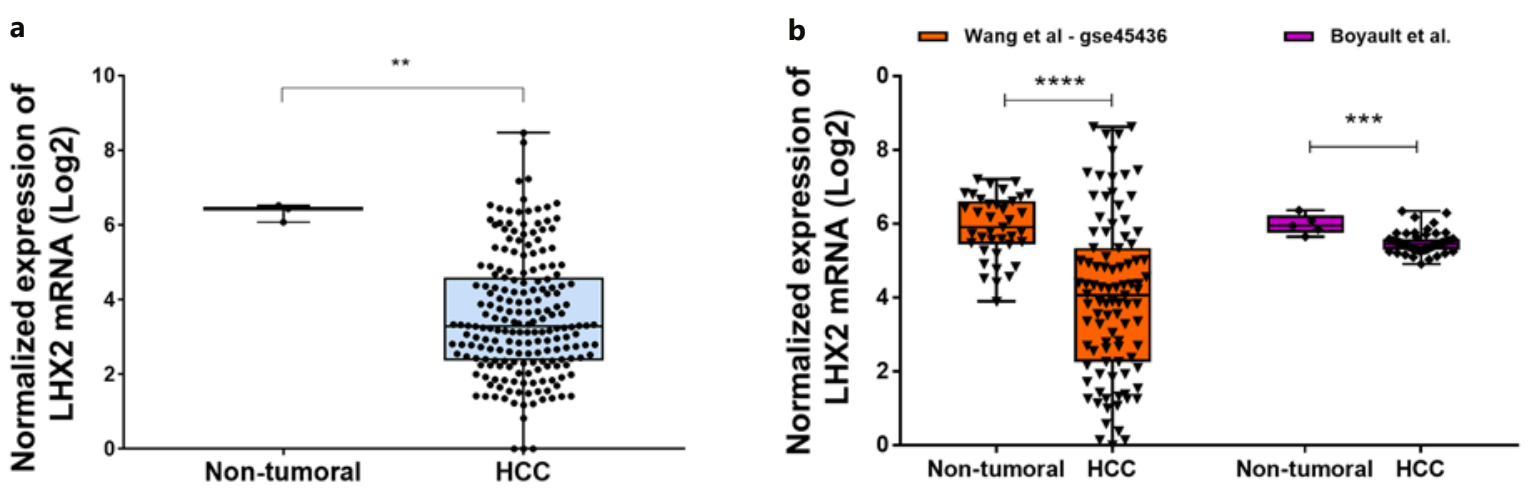

C

Mutated CTNNB1

Mutated AXIN1

Mutated ARID1A
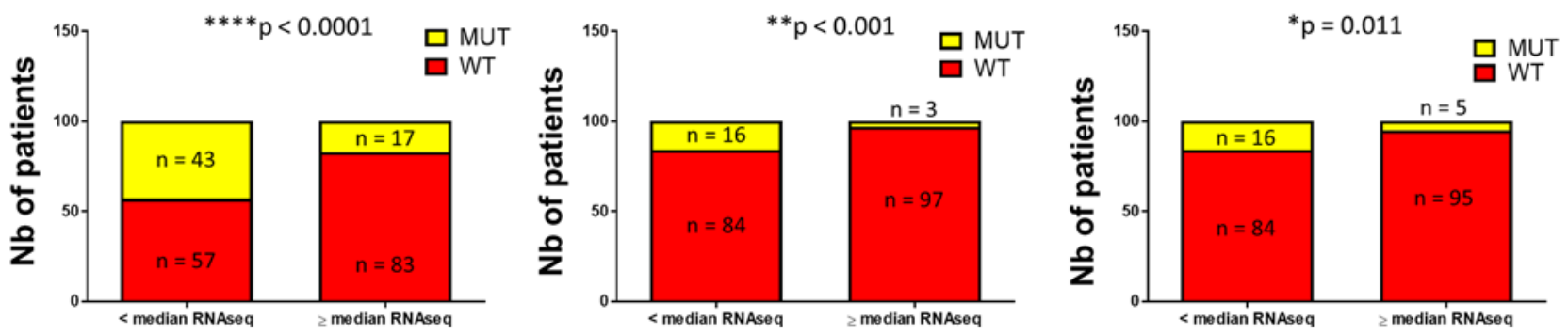

d

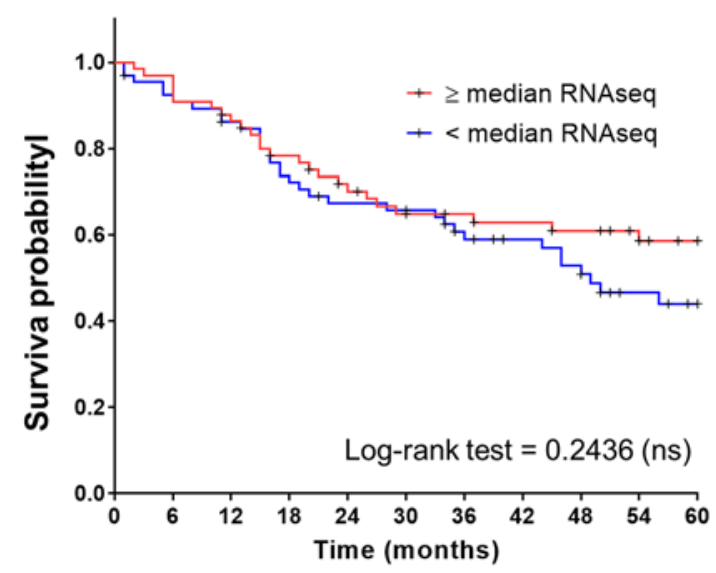

e

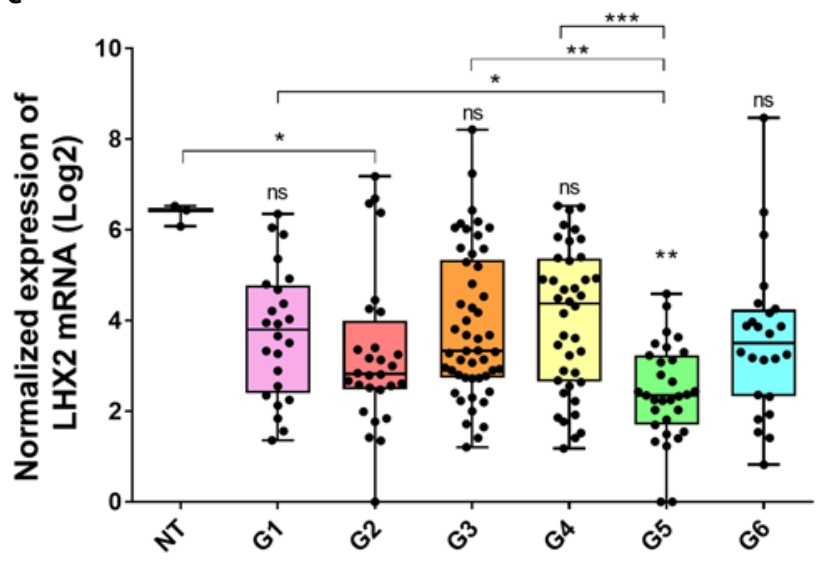

Fig. 1. Expression of the $L H X 2$ transcript in HCC. a, b Expression of $L H X 2$ in HCC and nontumoral samples from different datasets as indicated (a, our cohort dataset, online suppl. Table S1; b, left, Wang et al. [31] dataset, gse45436; b, right, Boyault et al. [9] dataset; unpaired Mann-Whitney test). c, d Correlative analyses between LHX2 expression and genetic features in 200 HCCs (c, two- tailed $\chi^{2}$ test; $\mathbf{d}$, log-rank test). e Expression of LHX2 in NT livers and different HCC subgroups from the Boyault et al. [9] dataset (Kruskal-Wallis test $p<0.0001$, Dunn's multiple comparisons post-test). a, b, e Boxes and whiskers represent mean \pm standard deviation. ns, not significant. ${ }^{*} p<0.05 ;{ }^{* *} p<0.01$; ${ }^{* * *} p<0.001$; $* * * * p<0.0001$. 

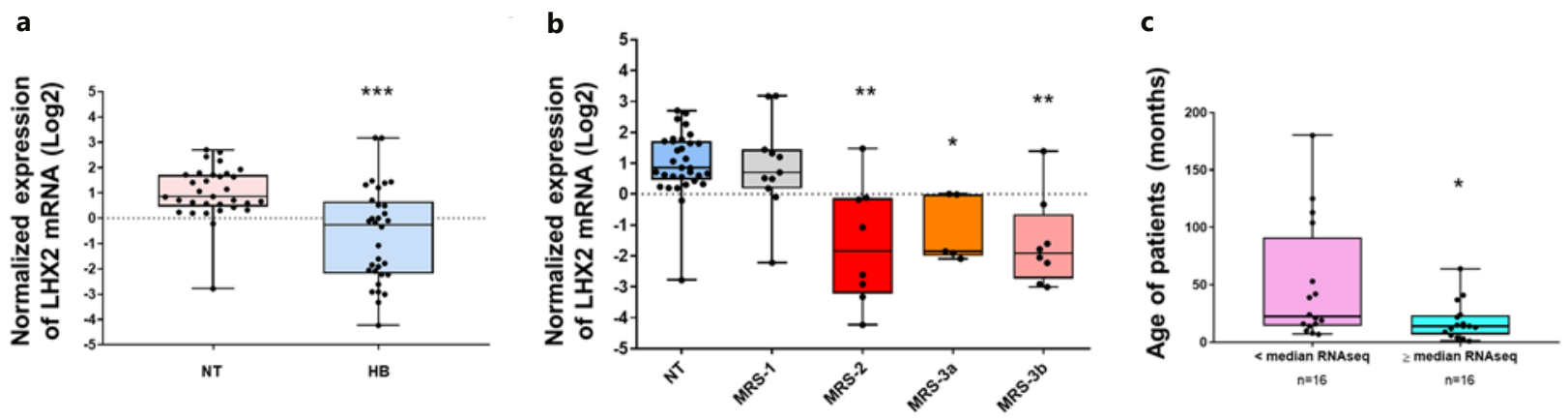

d

CHIC-HS

Multifocality

Wnt activation
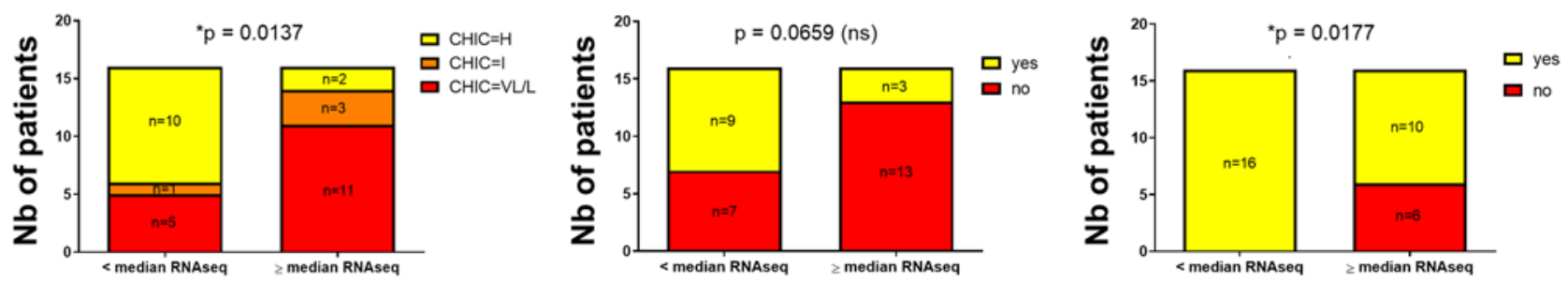

e

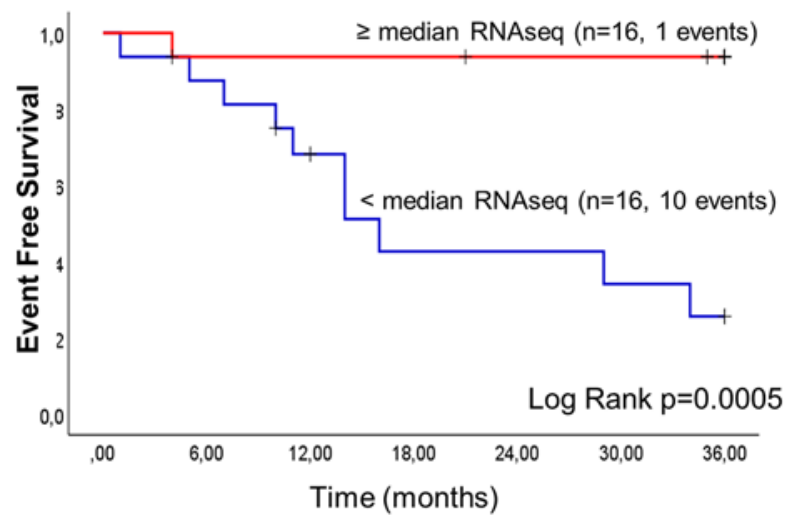

Blank

Sample 1
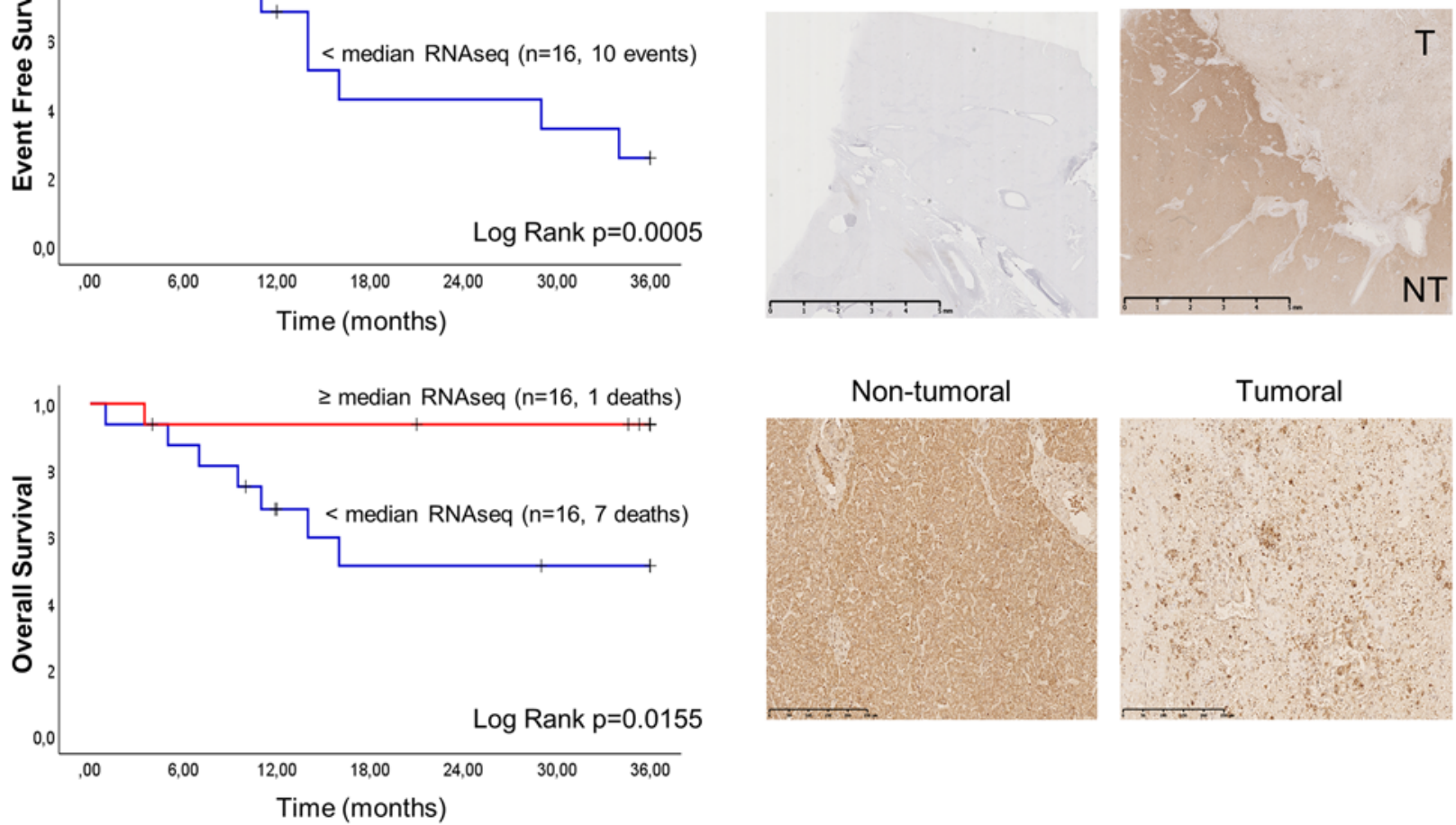

(For legend see next page.) 
sion of LHX2 in primary HSC results in an attenuated cell viability and migration [24].

Despite its strong connection with the Wnt signaling $[15,18,25,26]$, the role of the transcriptional factor LHX2 is totally unknown in liver cancers. Thus, we sought to investigate the effect of LHX2 in HCC and HB. We first interrogated the integrated knowledge database canSAR (https:// cansarblack.icr.ac.uk/) [27] to compare LHX2 transcript expression in nontumoral and tumoral tissues from various cancers. Thus, we assessed the deregulation of the LHX2 transcript in both HCC and HB using multiple transcriptomic datasets including data from open-source databases and our own investigations $[7,9,11]$. We completed our study using histological approaches, in vitro cell-based assays, RNA-sequencing, bioinformatics, and two animal models: the chorioallantoic membrane (CAM) assay in chick embryo $[4,28]$ and the axis duplication assay in Xenopus embryo. Overall, our work aimed to clarify the pathophysiological role of $L H X 2$ in liver cancers.

\section{Materials and Methods}

Liver Sample and Clinical Data

All patients were recruited in accordance with the European and French law and institutional ethical guidelines. Liver tissues were immediately frozen in isopentane with Snapfrost and stored at $-80^{\circ} \mathrm{C}$ until used for molecular studies. Samples were obtained from the Centre de Ressources Biologiques (CRB)-Paris-Sud (BRIF No. BB-0033-00089) with written informed consent, and the study protocol was approved by the French Government and the Ethics Committees of HEPATOBIO (HEPATOBIO project: CPP No. CO-15-003; CNIL No. 915640). Liver samples were clinically, histologically, and genetically characterized (online suppl. Tables S1, S2; for all online suppl. material, see www.karger.com/ doi/10.1159/000521595) $[7,9,11,29,30]$.

Transcriptomic Datasets

Transcriptomic data and datasets (Table 1) were as described in previous publications $[7,9,11,29-34]$ or uploaded from the NCBI's Gene Expression Omnibus (https://www.ncbi.nlm.nih. gov/geo, see the accession number and reference in the corresponding graph and/or figure legend) [35] or from the R2: Genomics analysis and visualization platform (https://r2.amc.nl). See online supplementary material for additional experimental procedures and data.

Fig. 2. Expression of the $L H X 2$ transcript and protein in $H B$. a, b LHX2 expression in $32 \mathrm{HB}$ and $32 \mathrm{NT}$ livers (Carrillo-Reixach et al. [11] dataset, gse132219) before (a, unpaired Mann-Whitney test) or after (b, Kruskal-Wallis test $p<0.0001$, Dunn's multiple comparisons test) tumor classification using the MRS method as indicated. c, d Correlative analyses between LHX2 expression and biological or clinical features (c, age of patients; unpaired MannWhitney test; d CHIC-HS [Children's Hepatic tumor Internation-

\section{Results}

\section{LHX2 Is Downregulated in Liver Cancers with Wnt} Activation

To study the pathophysiological relevance of the LHX2 gene in liver cancers, we first questioned the integrated knowledge database canSAR (https://cansarblack.icr. ac.uk/) [27]. In agreement with previous reports [15-19], the LHX2 transcript was upregulated in most cancer types but downregulated in liver cancer (online suppl. Fig. S1). To confirm this trend, we analyzed multiple transcriptomic datasets published by our consortium or by other groups in HCC and in HB (Table 1) [7, 9, 11, 29-34]. Our investigation confirmed the global downregulation of the LHX2 transcript in HCC compared to nontumoral tissues (Fig. 1a, b; Table 1). In these tumors, LHX2 downregulation significantly correlated with mutations in CTNNB1/ beta-catenin, AXIN1, and ARID1A genes, alcohol intake, largest nodules, HBV infection, metabolic syndrome, fibrosis, and fibrotic stroma (Fig. 1c; online suppl. Fig. S2, S6), but not with shorter survival (Fig. 1d). LHX2 downregulation was particularly visible in G5 (Fig. 1e), a group of HCC characterized by beta-catenin mutations, Wnt activation, and a decreased expression of genes involved in stress and immune response [9]. Finally, LHX2 expression was inversely correlated with the expression of the Wnt pathway-related genes $L G R 5, T B X 3$, and GLUL in two cohorts of HCC samples (online suppl. Fig. S3).

The LHX2 transcript was also decreased in HB (Fig. 2a, b; Table 1; online suppl. Fig. S4, S5a, b). Unlike HCC, LHX2 downregulation poorly correlated with Wnt activation (this variable including mutations in CTNNB1, APC, or AXIN1 genes) and did not correlate with CTNNB1 mutations, but it strongly correlated with several poor prognostic factors including the intermediate- and high-risk groups with Molecular Risk Stratification (MRS)-2, 3a, and 3b [11], older children, multifocal tumors, the Children's Hepatic tumor International Collaboration (CHIC)-high risk (HS) tumors [36], and event-free and overall survivals (Fig. 2b-e; online suppl. Fig. S5b-e, S6). Again, LHX2 was inversely correlated with the Wnt pathway-related genes LGR5, TBX3, and

al Collaboration-High Risk], multifocality, Wnt activation; twotailed $\chi^{2}$ test). e Top panel, event-free survival; bottom panel, overall survival; Kaplan-Meier curves, log-rank test. a-c Boxes and whiskers represent range from min to max. $\mathbf{f}$ Representative immunostaining of LHX2 in HB sample 1 ( $\mathrm{T}$, tumor) and paired NT liver. Scale bars are as indicated. ns, not significant; NT, nontumoral. ${ }^{*} p<0.05 ;{ }^{* *} p<0.01 ;{ }^{* *} p<0.001$.
LHX2 Is a Tumor Suppressor in Hepatocyte-Derived Liver Cancers
Liver Cancer

DOI: $10.1159 / 000521595$ 
a

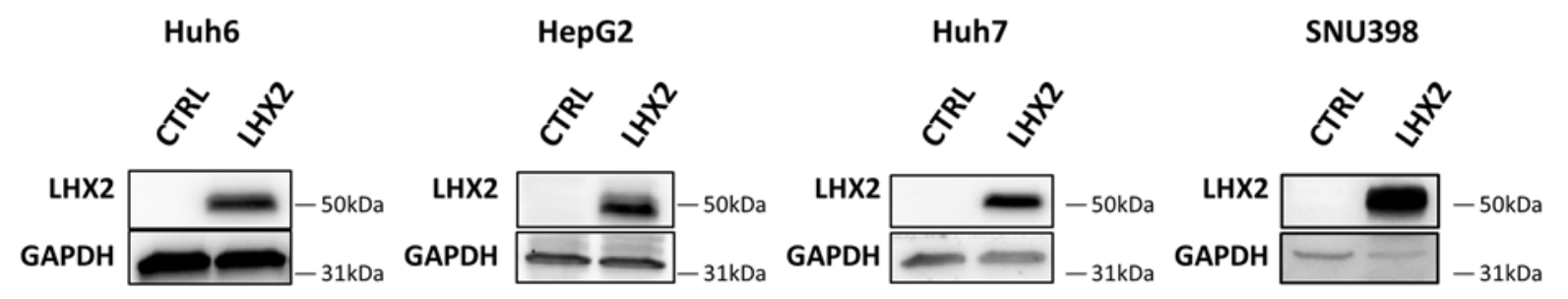

b

Huh6

HepG2

Huh7

SNU398
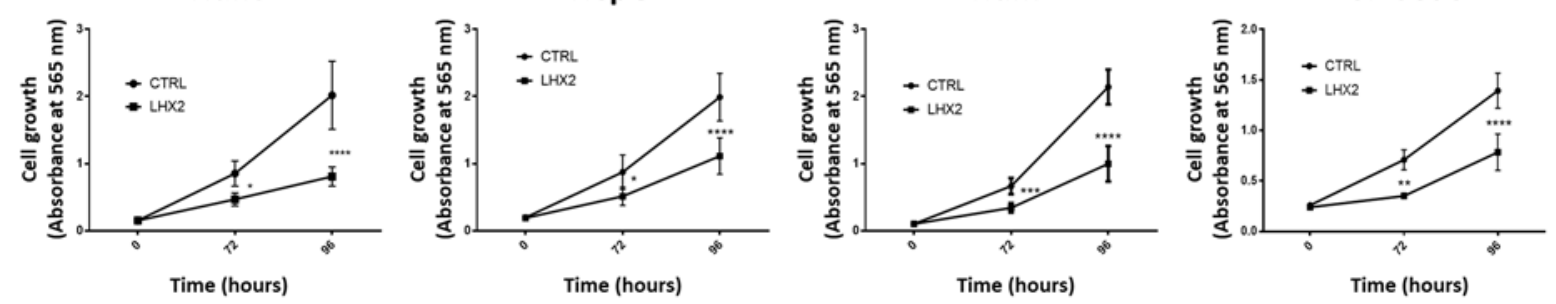

c

Huh6

HepG2

Huh7

SNU398

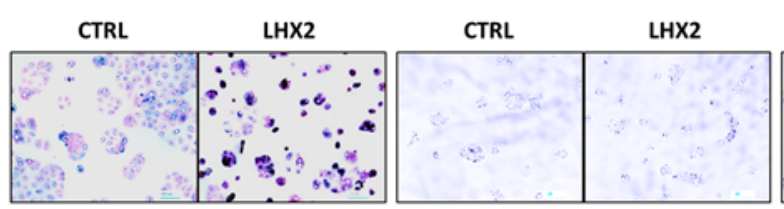

CTRL LHX2
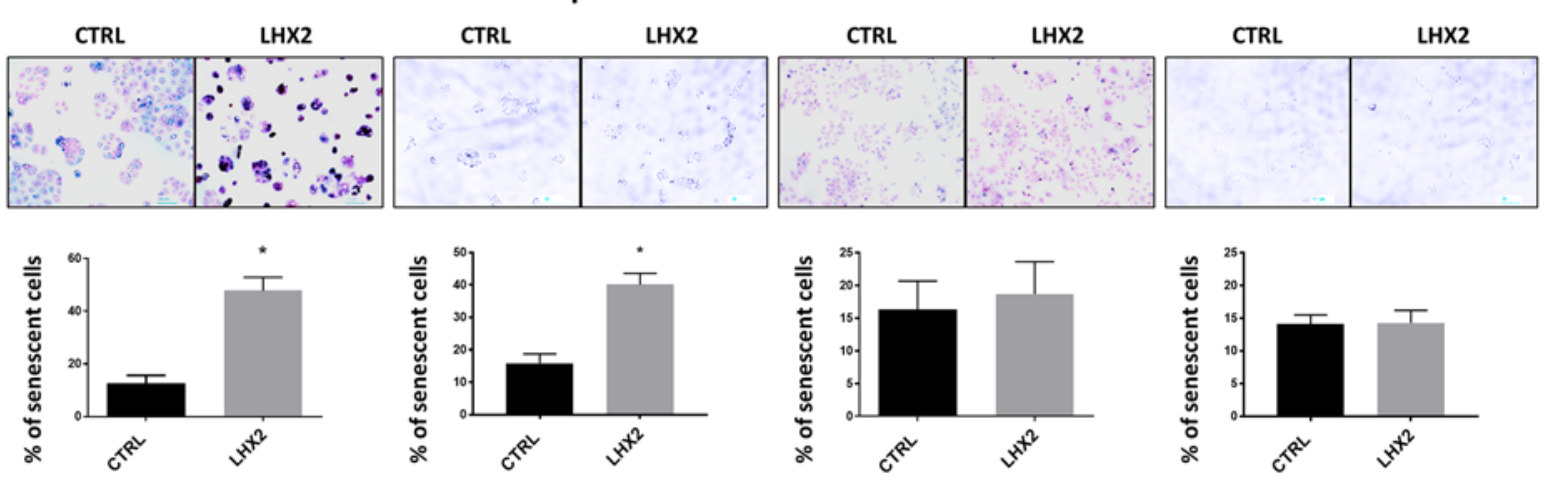

d

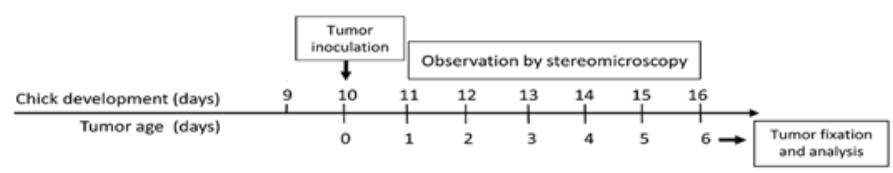

Huh6
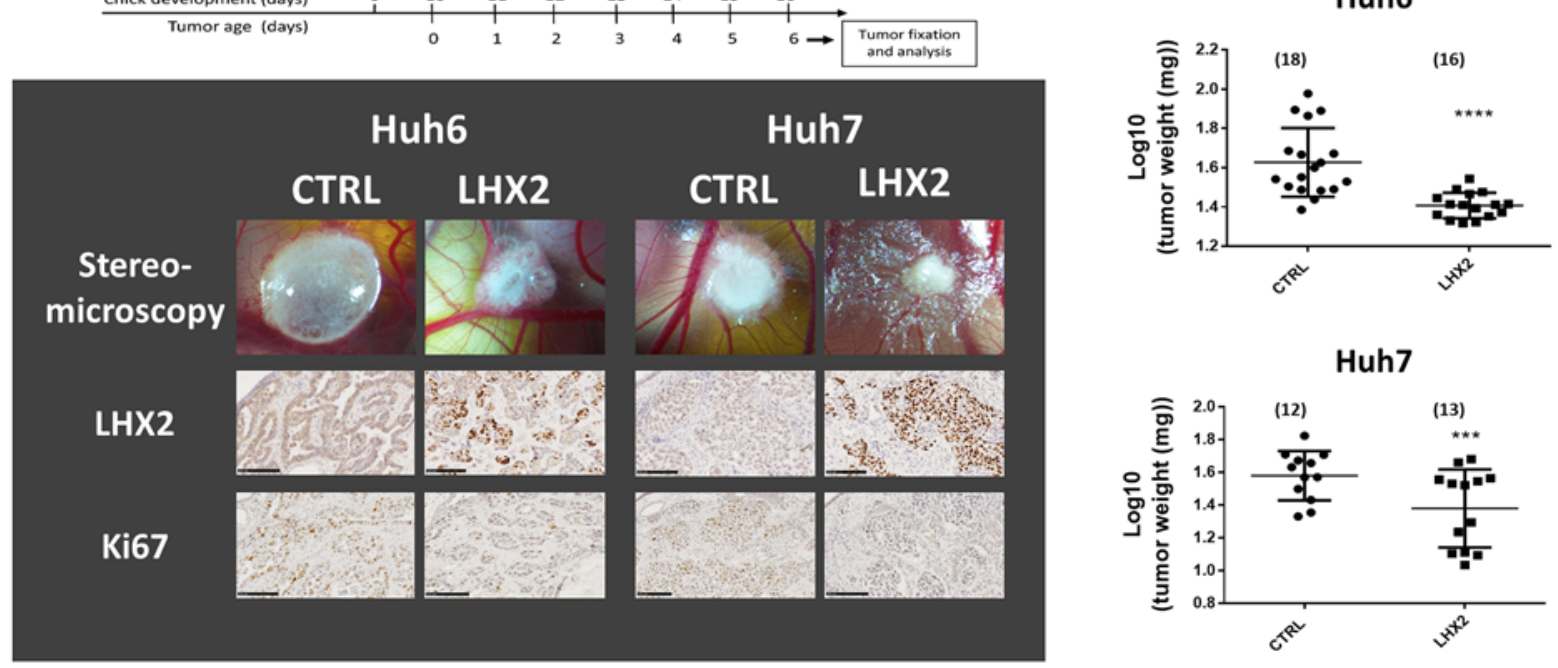

3

(For legend see next page.) 
GLUL in two cohorts of HB samples (online suppl. Fig. S7). Next, we performed a GSEA analysis using $32 \mathrm{HB}$ samples [11] stratified into two groups according to LHX2 expression (low vs. high expression) and using specific gene sets related to MAPK/ERK, Wnt, and apoptosis signaling pathways. This analysis revealed that the MAPK/ERK and Wnt pathways are deregulated in HBs with low LHX2 expression compared with HBs with high LHX2 expression (online suppl. Fig. S8a, b). In addition, apoptotic genes were increased in HBs with high LHX2 expression (good prognosis) compared with tumors with low LHX2 expression (bad prognosis) (Fig. 2b-e; online suppl. Fig. S8c). Using normal and tumoral pediatric liver samples, we confirmed by immunostaining the downregulation of LHX2 protein in $\mathrm{HB}$ and noted a high inter- and intra-tumoral heterogeneity of the protein expression in cancerous cells among the samples (Fig. 2f; online suppl. Fig. S9). Altogether, these data suggested a functional link between LHX2, MAPK/ERK, and Wnt signals and liver carcinogenesis.

\section{LHX2 Impedes Liver Cancer Development in vitro and} in vivo

In view of the above results, we hypothesized that LHX2 might act as a tumor suppressor in the liver. In agreement with this, HCC-derived Huh7 and SNU398 cells, as well as HB-derived Huh6 and HepG2 cells (online suppl. Table S3), did not express the protein (Fig. 3a). In addition, the LHX2 transcript was hardly detectable in Huh7, Huh6, and HepG2 cells (data not shown; published RNA-seq data [7]). Thus, we developed LHX2-expressing Huh6, HepG2, Huh7, and SNU398 cell lines by lentiviral transduction (Fig. 3a). The ectopic expression of LHX2 significantly inhibited the growth and migration of HCC and HB cells (Fig. 3b; online suppl. Fig. S10a), with the exception of HepG2 cells which do not migrate in our cell culture conditions (data not shown). In HBderived Huh6 and HepG2 cells, LHX2 did not trigger caspase-dependent apoptosis but induced senescence, as shown by a significant increase in beta-galactosidase-positive cells and p21 biomarker (Fig. 3c; online suppl. Fig.

Fig. 3. LHX2 is a tumor suppressor in liver cancers. a Transduced Huh6, HepG2, Huh7, and SNU398 cells (as indicated above the panels) expressing LHX2 or an empty cassette (CTRL). Representative blots of 3 independent experiments are shown in cropped images. b Growth (absorbance at $565 \mathrm{~nm}$ ) of Huh6, HepG2, Huh7, and SNU398 as indicated ( $n=3-6$, two-way ANOVA, $p<0.0001$, Sidak's multiple comparisons post-test). c Percentage of senescent Huh6, HepG2, Huh7, and SNU398 as indicated. Top: representative experiment. Bottom: bar graph recapitulating means $\pm \mathrm{SD}$ ( $n=3-6$, Wilcoxon matched-pairs signed rank test). d Top panel:
S10b, c). Unlike HB cells, LHX2 increased caspase-dependent apoptosis but not senescence in HCC-derived Huh7 and SNU398 cells (Fig. 3c; online suppl. Fig. S10c) suggesting a differential response of these two cell lines to forced LHX2 expression. In vivo, LHX2 impeded both $\mathrm{HB}$ and HCC tumor growth with the CAM assay (Fig. $3 \mathrm{~d}$ ) $[4,28]$. Engrafted LHX2-expressing Huh6 and Huh7 cells formed smaller tumors after 6 days of growth with a decreased staining of Ki67-positive cells. Microscopically, LHX2 protein was located in the nucleus of engrafted cells (see LHX2 images). Altogether, these data demonstrated that LHX2 inhibits the growth of HCC and HB cells by, respectively, a pro-apoptotic and pro-senescent mechanism and therefore acts as a tumor suppressor in the liver.

\section{LHX2 Inhibits the MAPK/ERK Pathway in HB and HCC Cells}

To elucidate the molecular alterations occurring in hepatoma cells after forced expression of LHX2, we performed a phosphokinase assay using proteins extracted from parental or LHX2-expressing Huh6 cells. Out of 43 human kinases tested, 7 were slightly dephosphorylated by LHX2 expression (Fig. 4a; online suppl. Fig. S11). Among them, we noticed a decreased phosphorylation of ERK1/2, two kinases being the main effectors of the pro-oncogenic MAPK/ERK pathway (Fig. 4a) $[4,37]$. Complementary immunoblots confirmed the dephosphorylation of ERK1/2 in both LHX2-expressing Huh7 and Huh6 cells (Fig. 4b, c). To explain this dephosphorylation, we measured the expression of mitogen-activated protein kinase (MPK)/dual-specific (DUSP) phosphatases, a group of phosphatases that specifically regulate MAPK activity [38]. Our investigation showed that DUSP5 and DUSP6 phosphatases increased in response to LHX2, while DUSP3 remained unchanged (Fig. 4b, c). LHX2 expression partly correlated with DUSP5 and DUSP6 expressions in HCC and HB (online suppl. Fig. S12, S13, respectively). Altogether, these results demonstrated that LHX2 inhibits the MAPK/ERK signaling pathway in HCC and HB cells, likely through the induction of DUSP5 and DUSP6 phosphatases.

timeline illustrating the CAM assay. Bottom panel: top lanes show representative stereomicroscopic images of 6-day tumors after implantation of CTRL or LHX2-expressing Huh6 or Huh7 cells as indicated. Middle lanes show LHX2 immunostaining. Bottom lanes show Ki67 immunostaining. Scale bar, $100 \mu \mathrm{m}$. Right panel: mass of 6-day tumors (see number of eggs analyzed per group in brackets). Horizontal line and whiskers represent mean \pm SD (Wilcoxon matched-pairs signed rank test). ${ }^{*} p<0.05 ;{ }^{* *} p<0.01 ;{ }^{* * *} p$ $<0.001{ }^{* * * *} p<0.0001$. 
a

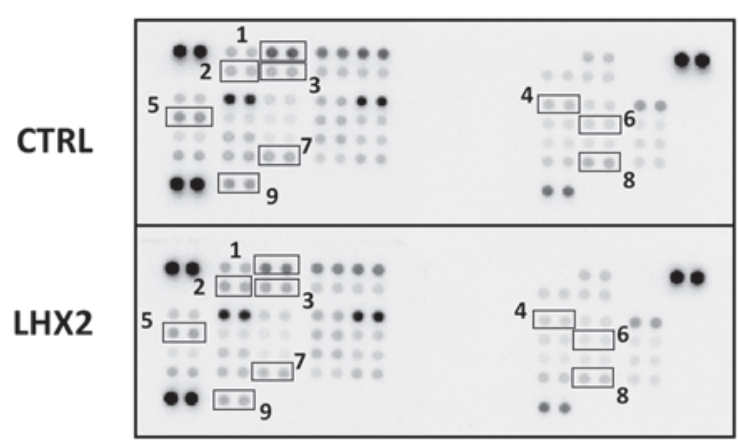

b Huh7
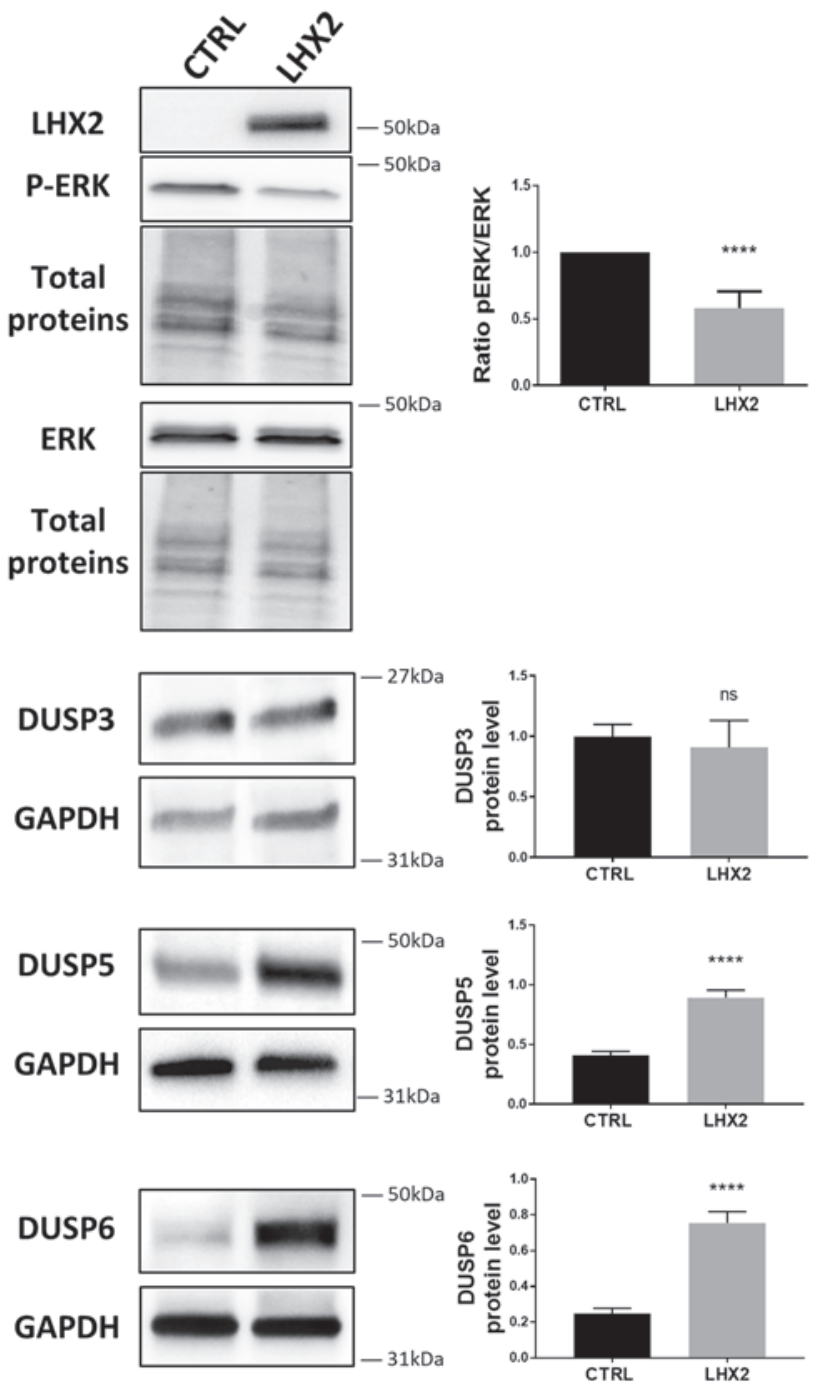

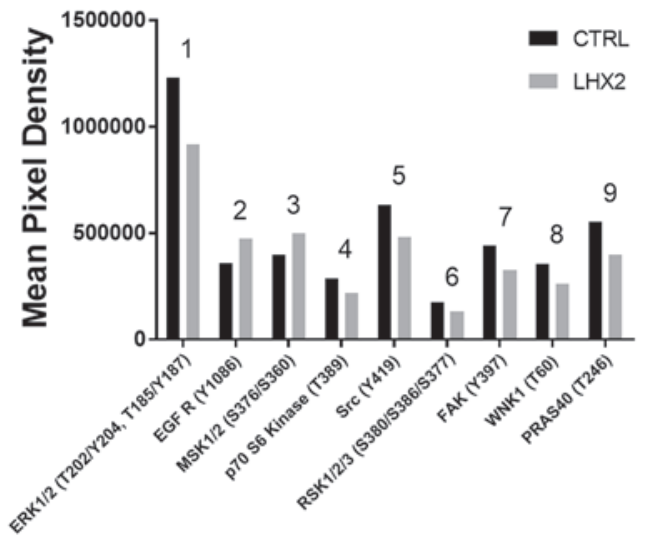

c

Huh6
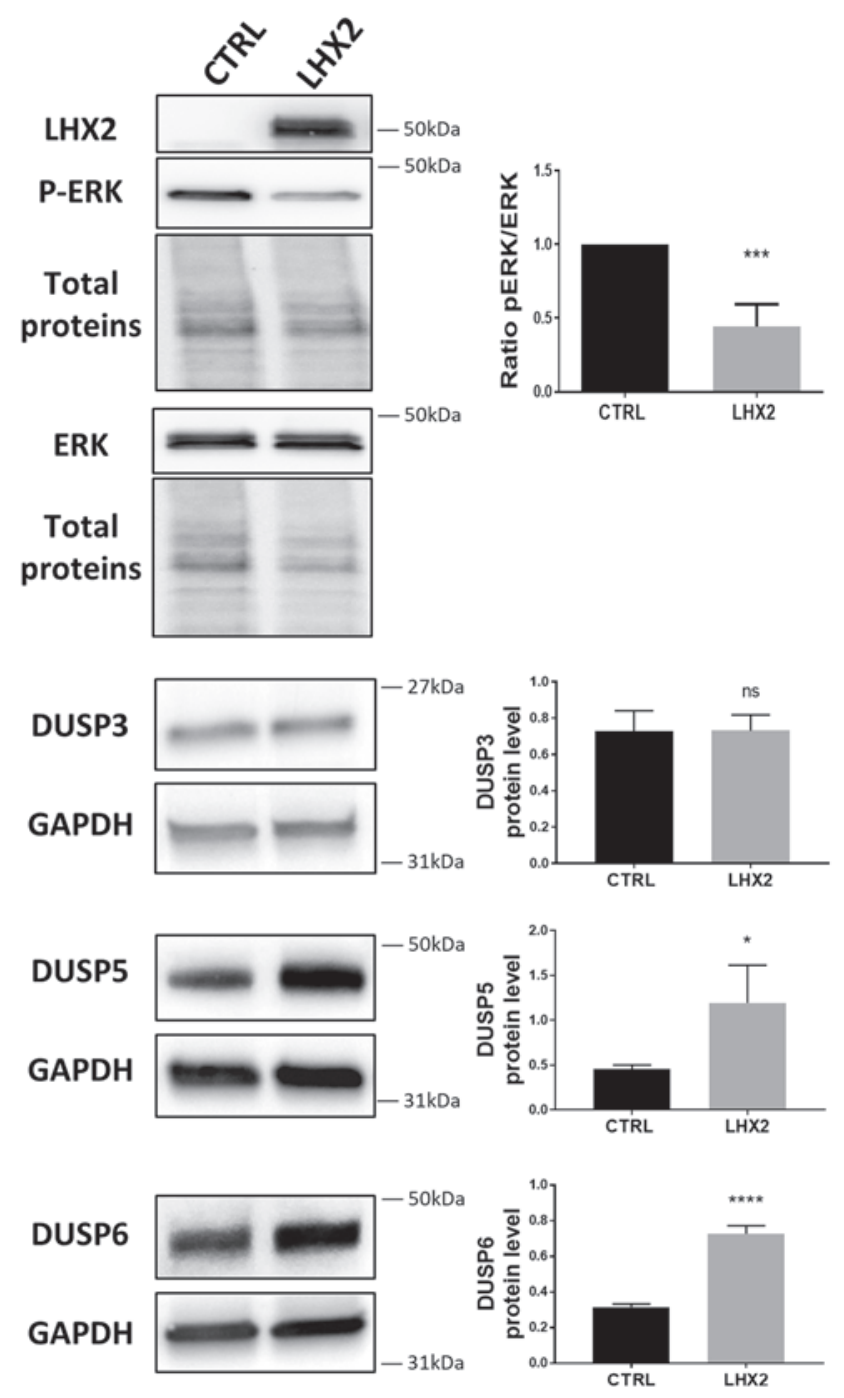


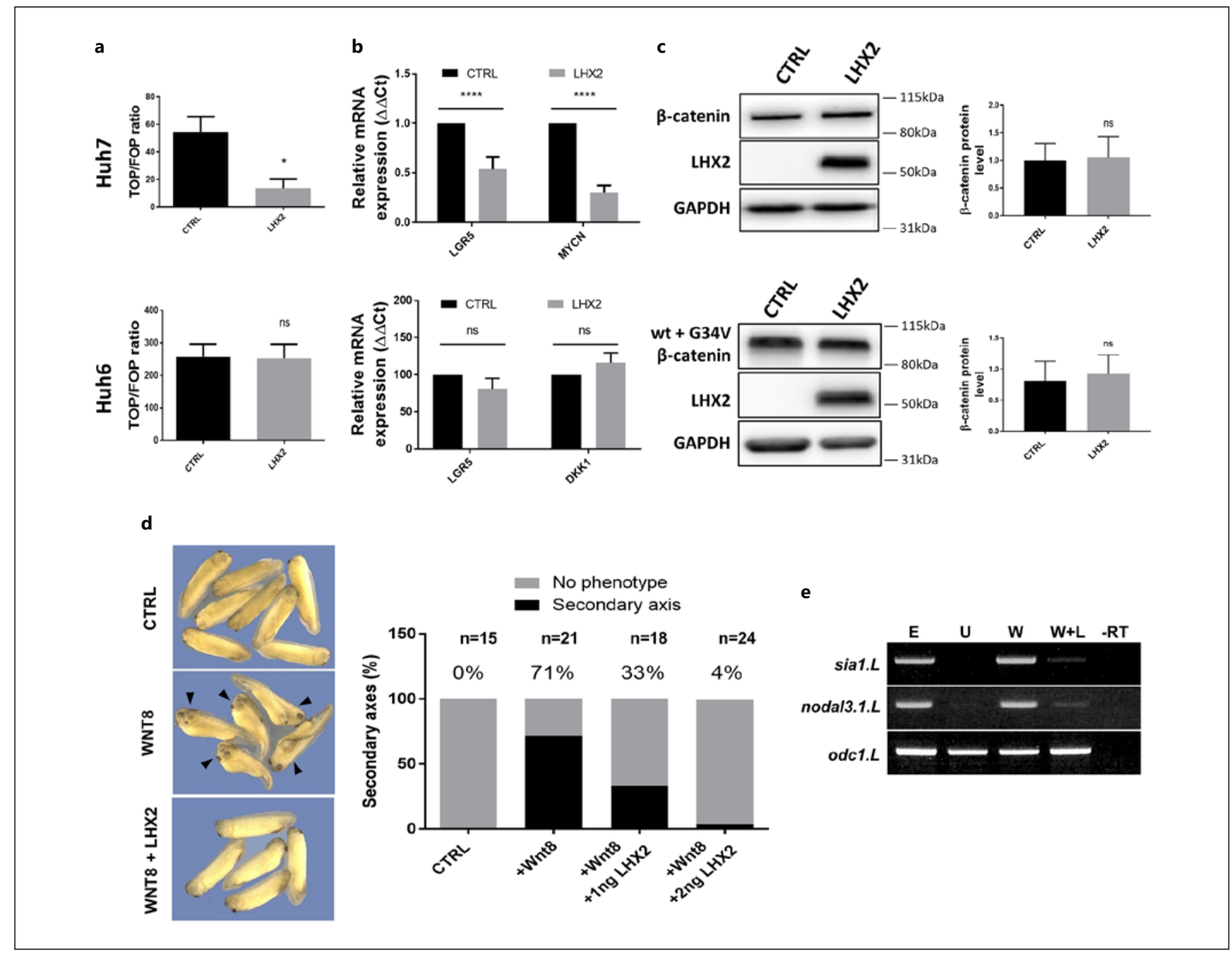

Fig. 5. LHX2 inactivates the Wnt signal in a hepatoma cell-dependent manner. a Wnt transcriptional activity (TOP/FOP ratio) in CTRL (control) or LHX2-expressing Huh7 (top) and Huh6 (bottom) cells. Bar graphs recapitulate means \pm SD $(n=4-7$, Wilcoxon matched-pairs signed rank test). b Expression of Wnt pathwayrelated genes (as indicated) in CTRL and LHX2-expressing Huh7 (top) and Huh6 (bottom) cells. Bar graphs recapitulate means \pm $\mathrm{SD}(n=6$, data reported as quantity of control set at 1 , multiple $t$ tests). c Relative expression of wild-type (wt) and mutated (G34V) beta-catenin proteins (as indicated on the left of the blots) in CTRL (control) or LHX2-expressing Huh7 (top) and Huh6 (bottom) cells. Left panel: representative blots in cropped images. Right panel: bar graph recapitulate means $\pm \mathrm{SD}$ ( $n=4$, Wilcoxon matched-

Fig. 4. LHX2 inhibits the MAPK/ERK signal by inducing DUSP5/6 phosphatases. a Phosphorylation level of various kinases in CTRL (control) and LHX2-expressing Huh6 cells. Left panel: screening experiment. Right panel: quantification in mean pixel density. b, $\mathbf{c}$ Relative expression of phospho-ERK1/2 (ERK), ERK1/2 (ERK), DUSP3, DUSP5, and DUSP6 in CTRL or LHX2-expressing Huh7 pairs signed rank test). d Wnt signaling activity in noninjected Xenopus embryos (CTRL) or embryos injected with wnt8 mRNA (WNT8) or a combination of wnt8 and LHX2 mRNAs (WNT8+LHX2). Left panel: representative images of larvae (arrow heads: larvae with secondary axis). Right panel: bars represent the percentage of embryos with no phenotype or a secondary axis (see number of analyzed embryos above the corresponding bar, $\chi^{2}$ test $p<0.0001)$. e Expression of Wnt pathway-related target transcripts (sia1.L, siamois; nodal3.1L, nodal) in total Xenopus embryos (E), noninjected embryos (U), injected with wnt8 mRNA (W), or injected with wnt8 + LHX2 mRNAs $(\mathrm{W}+\mathrm{L})$. Internal control, ornithine decarboxylase transcript (odc1.L). RT-lane: no reverse transcription. ns, not significant. ${ }^{*} p<0.05 ;{ }^{* * * *} p<0.0001$.
LHX2 Is a Tumor Suppressor in Hepatocyte-Derived Liver Cancers (b) and Huh6 (c) cells. Left panel: representative blots in cropped images (loading control: total proteins or GAPDH as indicated). Right panel: bar graph presenting means \pm SD $(n=6-8$, MannWhitney matched-pairs signed rank test). ns, not significant. ${ }^{*} p<$ $0.05 ;{ }^{* * *} p<0.001 ;{ }^{* * * *} p<0.0001$. 
a
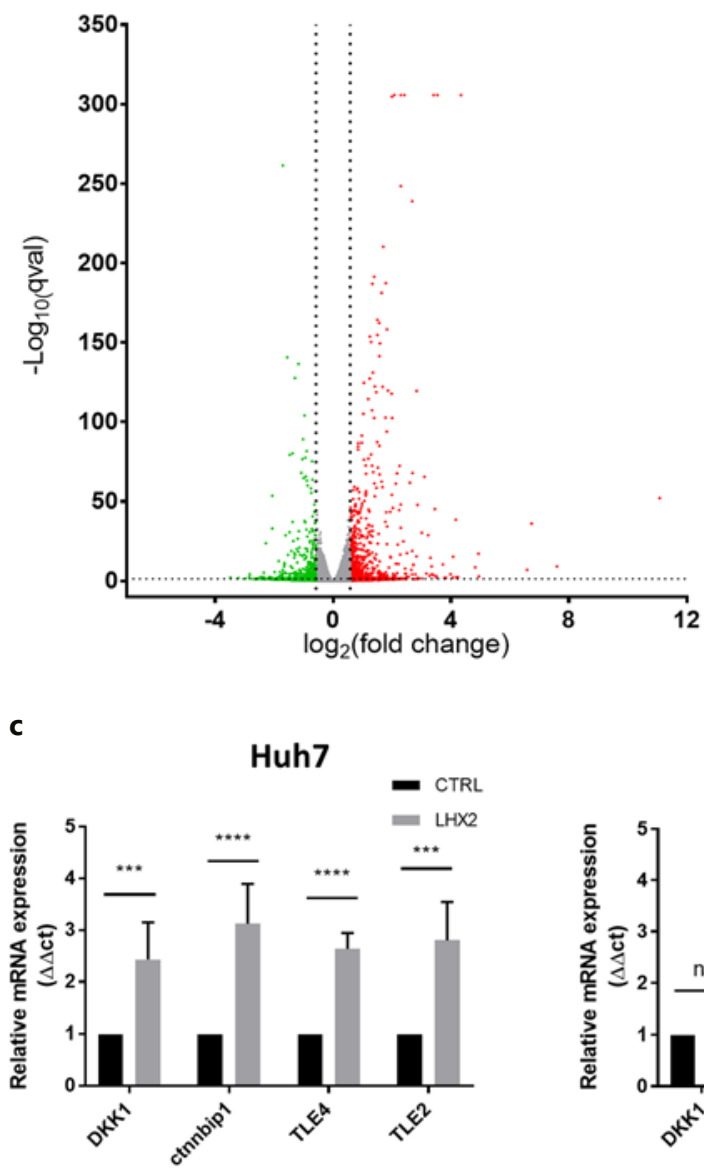

d

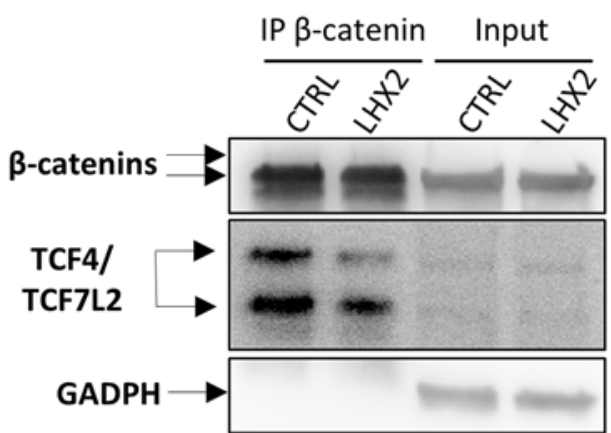

Huh7

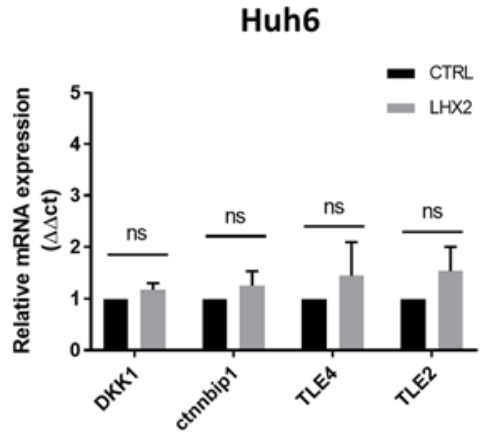

Huh6
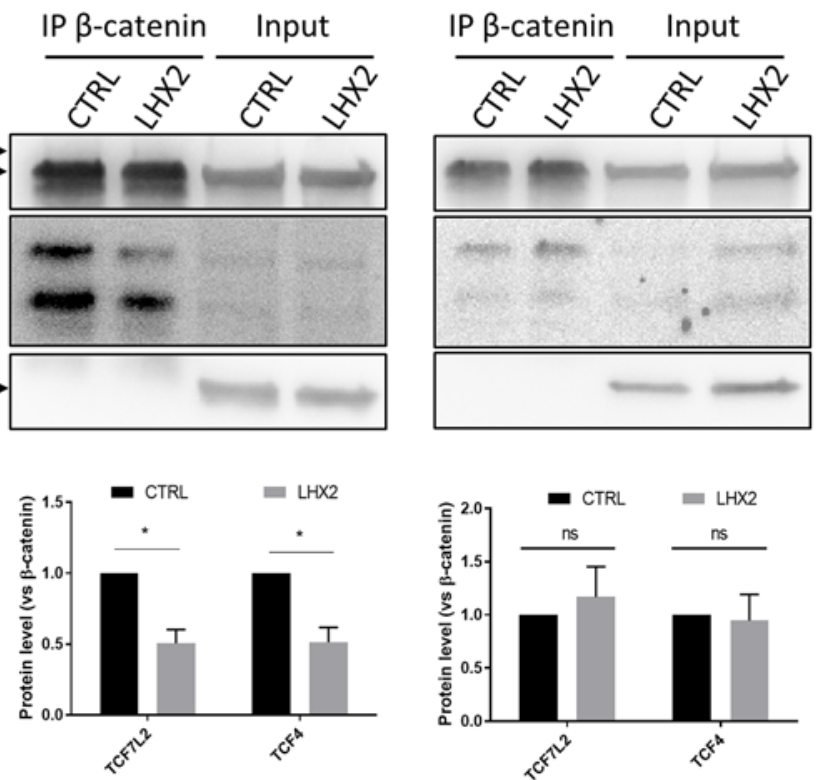

GO:0030111 (Regulation of Wnt signaling pathway)

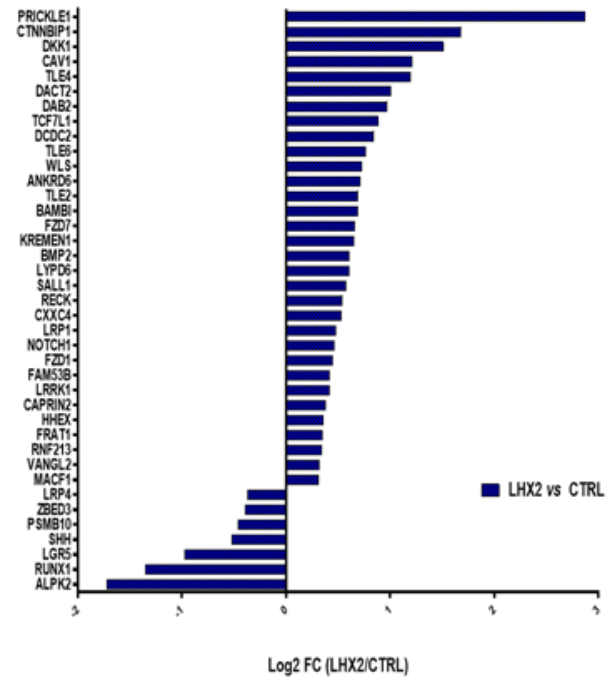

HepG2

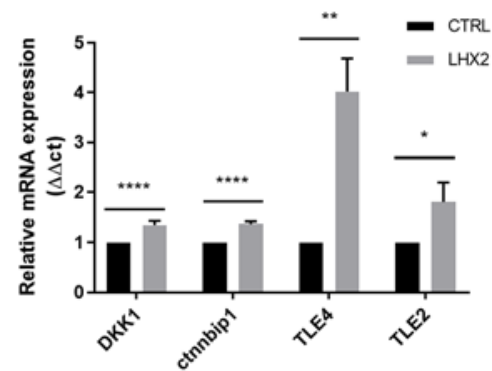

HepG2
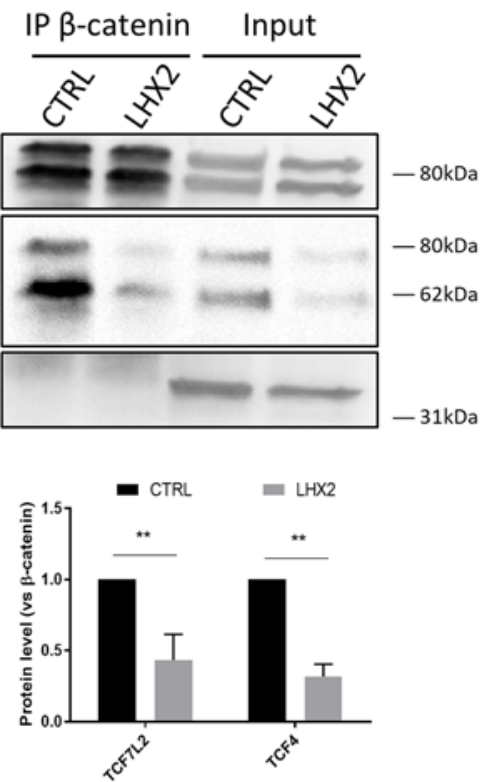

(For legend see next page.) 


\section{LHX2 Inhibits Wnt Signaling in a Cell-Dependent Manner}

As Wnt pathway activation is a molecular hallmark of liver cancer pathogenesis $[1-3,7,39]$, we investigated the impact of LHX2 on beta-catenin transcriptional activity in Huh6, HepG2, SNU398, and Huh7 cells [40]. LHX2 did not affect beta-catenin transcriptional activity or LGR5 and DKK1 mRNA expression in Huh6 cells (G34V point mutation in beta-catenin gene), but it significantly inhibited the Wnt signal and induced a decrease in Wnt targets LGR5 and MYCN in Huh7 cells (wild-type for beta-catenin gene) (Fig. 5a, b). LHX2 also inhibited the Wnt pathway in HepG2 and SNU398 cells, which carry a large deletion in exon 3 of the CTNNB1 gene and the S37C point mutation, respectively (online suppl. Fig. S14). Concomitantly, the beta-catenin protein level remained unaffected in all cell lines (Fig. 5c; online suppl. Fig. S14). Because the capacity of LHX2 to inhibit Wnt signaling appeared cell-specific and independent of beta-catenin mutations, we performed in vivo analysis in the Xenopus embryo using the axis duplication assay. Following the induction of Wnt-dependent larvae body axis duplication with the soluble ligand Wnt8 (Fig. 5d) or a dominantnegative form of Gsk3-beta (GSK3B-DN, online suppl. Fig. S15), human $L H X 2$ transcript co-injection resulted in a dose-dependent decrease in dorsal axis duplication associated with a lower expression of the Xenopus Wnt signaling-related genes Siamois and Nodal (Fig. 5d, e; online suppl. Fig. S15). Altogether, these results demonstrated the negative regulation of the Wnt pathway by LHX2, except in Huh6 cells.

\section{LHX2 Inhibits Wnt Signaling by Multiple Regulatory Mechanisms}

To explore the molecular mechanisms underlying the antitumor effect of LHX2 in liver cancer, we performed comparative RNA-seq analysis in LHX2-expressing and control Huh7 cells. Using a cutoff fold change of 1.5 and a cutoff $p$ value of $0.05,576$ (including LHX2) and 251 genes were significantly and, respectively, up- and downregulated in LHX2-expressing cells

Fig. 6. LHX2 inactivates the Wnt signal by multiple molecular mechanisms. a Volcano plot of gene expression fold change ( $X$ axis, $\log _{2}$ ) versus $q$ values ( $Y$-axis, $\log _{10}$ ) in LHX2-expressing versus control (CTRL) Huh7 cells. b Gene Set Enrichment Analysis related to the regulation of the Wnt pathway. c Relative expression of Wnt pathway-related genes in CTRL or LHX2-expressing Huh7 (left panel), Huh6 (middle panel), and HepG2 (right panel) cells. Bar graphs recapitulate means \pm SD $(n=3-6$, multiple $t$ tests). d Association of TCF4/TCF7L2/beta-catenin in each CTRL or
(Fig. 6a; online suppl. Fig. S16 and Table S7). To find the canonical pathways, disease states, biological functions, and molecular networks associated with LHX2 expression, we interrogated the Ingenuity Pathway Analysis (IPA) program (http://www.ingenuity.com) using our list of 827 deregulated genes. In agreement with the phenotypical changes shown in Figure 3 and online supplementary Figure S10, the pathways deregulated in LHX2-expressing Huh7 cells were related to cellular movement, cell growth and proliferation, and cell death and survival, but also cell-to-cell signaling and interaction, molecular transport, and lipid metabolism (online suppl. Fig. S17a). In addition, disease and toxicological functions associated with cancer, organismal injury, and hepatic system diseases were also strongly altered (online suppl. Fig. S17b, c). By Gene Set Enrichment Analysis (GSEA), we found an enrichment of several key biological processes, cellular components, and molecular functions (online suppl. Fig. S1820). Among them, Wnt pathway-related genes were significantly enriched, including numerous regulatory factors involved in the inhibition of Wnt signaling and the repression of the nuclear beta-catenin/TCF/LEF transcriptional complex (Fig. 6b). The increased expression of DKK1, CTNNBIP1/ICAT, TLE2, and TLE4 mRNA was confirmed by RT-qPCR in LHX2-expressing Huh7 (Fig. 6c, left panel). As expected, these genes remained unchanged in Huh6 cells (Fig. 6c, middle panel), although they increased in LHX2-expressing HepG2 cells (Fig. 6c, right panel). Western blot analyses confirmed the increase in TLE4 in LHX2-expressing Huh7 cells and in TLE2 in LHX2-expressing HepG2 cells (online suppl. Fig. S21). To gain further insight into LHX2-mediated Wnt signaling inhibition, we performed co-immunoprecipitation experiments. As shown in Figure 6d, LHX2 induced the dissociation of beta-catenin and T-cell factor 4/transcription factor 7-like 2 (TCF4/TCF7L2) in Huh7 and HepG2 cells, but not in Huh6 cells. We also noted a decrease in TCF4/ TCF7L2 expression in LHX2-expressing HepG2 cells (compare input lanes in the middle panel of Fig. 6d; on-

LHX2-expressing cell line as indicated (beta-catenin immunoprecipitation followed by TCF4/TCF7L2 immunodetection). Top panel: representative blots in cropped images (GAPDH, loading control in Input lanes). HepG2 cells expressed two forms of betacatenin, wild-type and exon 3-4 deleted. Bottom panel: bar graph recapitulating means $\pm \mathrm{SD}(n=3$, two-way ANOVA, Sidak's multiple comparisons post-test). ns, not significant. ${ }^{*} p<0.05$; ${ }^{* *} p<$ $0.01 ;{ }^{* * *} p<0.001{ }^{* * * *} p<0.0001$.
LHX2 Is a Tumor Suppressor in Hepatocyte-Derived Liver Cancers
Liver Cancer

DOI: $10.1159 / 000521595$ 
line suppl. Fig. S22). Altogether, these data demonstrated that LHX2 has a double-negative regulatory action on Wnt signaling: it induces the expression of multiple Wnt inhibitors and prevents the assembly of the betacatenin/TCF/LEF transcriptional complex.

\section{Discussion}

The members of the LIM homeobox family are key transcriptional regulators that actively participate in cell specialization, tissue morphogenesis, and organ modeling during embryogenic development. However, they are also highly involved in tumorigenic processes $[13,14,16,17$, 19]. In this work, we report the tumor suppressive role of LHX2 in both adult and pediatric liver cancers. We first show that the expression of the LHX2 transcript is decreased in HB and HCC using multiple datasets [7, 9, 11, 29-34]. In HCC, LHX2 mRNA downregulation was particularly associated with the G5 group of tumors [9], a group characterized by Wnt activation and CTNNB1 mutations, and its expression was correlated with the presence of CTNNB1 mutations and the expression of Wnt pathwayrelated genes. In $\mathrm{HB}$, a cancer characterized by Wnt alteration and CTNNB1/beta-catenin mutations but less heterogeneous than HCCs $[7,9]$, we found a strong correlation between the downregulation of LHX2 and poor prognostic parameters including higher patient age, intermediate- and high-risk tumors according to $\mathrm{CHIC}$ and MRS- $2 / 3 \mathrm{a} / 3 \mathrm{~b}$ stratification $[11,36]$, and patients' survival, but not CTNNB1/beta-catenin mutations. Thus, LHX2 decrease is a prognostic marker in HB. Furthermore, we demonstrated that LHX2 inhibits the growth, survival, and migration of hepatoma cells in vitro and the development of experimental HB and HCC tumors in vivo. Interestingly, our data are in contradiction with the well-known pathological function of this gene in other solid tumors and leukemia. Indeed, LHX2 is upregulated in many cancers, a result confirmed by our data collected from the canSAR database (online suppl. Fig. S1), and it participates in tumor development through the regulation of multiple oncogenic pathways including Wnt [15-17, 19, 41]. Kuzmanov et al. [16] reported that LHX2 is upregulated during TGF $\beta$-induced epitheliomesenchymal transition in breast cancer, while other groups showed that LHX2 promotes nasopharyngeal carcinoma and pancreatic ductal adenocarcinoma through Wnt activation by supporting TCF4 expression or facilitating the interaction between beta-catenin and TCF4 $[15,18]$. Together, these data demonstrate the key role of LHX2 in Wnt signaling-associated carcinogenesis.
Given the role of LHX2 in proliferation and tumor growth, we sought to evaluate whether LHX2 interferes with different pathways involved in liver carcinogenesis. Using a phosphokinase array, we found decreased phosphorylation of ERK1/2 on threonine 202 and tyrosine 204 in LHX2-expressing cells, a posttranslational modification essential to the MAPK/ERK signaling cascade. Signaling via ERK1/2 kinase is crucial for the development and progression of HCC $[4,42]$, but its role in $\mathrm{HB}$ has also been documented [43]. Moreover, ERK1/2 dephosphorylation and MAPK/ERK signaling inactivation mediated by either pharmacological inhibitor or microRNAs decreases HCC cell viability $[4,44]$. We also found that LHX2 potentiates the expression of DUSP5 and DUSP6, two phosphatases known to dephosphorylate and inactivate ERK1/2 kinases in hepatoma cells [38]. Of note, the expression of these two phosphatases correlated slightly with that of LHX2 in HCC and HB. Therefore, our data suggest the tumor-suppressing role of LHX2 in HCC and $\mathrm{HB}$ through the induction of DUSP5/6 and the inactivation of the MAPK/ERK pathway (Fig. 7).

The Wnt pathway is another crucial pathway in liver development and hepatic malignancies [1-3, 7, 39]. Several studies have reported a connection between LHX2 and Wnt signaling. Hsu et al. [25] demonstrated that LHX2 regulates the timing of beta-catenin-dependent cortical neurogenesis. Others showed that LHX2 can promote tumor growth and invasion through Wnt pathway activation and TCF4/beta-catenin complex stabilization $[15,18]$. In contradiction with these two reports, Zhang et al. [26] reported inhibition of Wnt/beta-catenin signaling by LHX2 during forebrain development in the Xenopus embryo. Our work clearly suggests an inactivating role of LHX2 on Wnt signaling in hepatoma cells and Xenopus embryo. Collectively, our data also demonstrate the strong biological and functional connection between LHX2 and the Wnt pathway during embryogenesis and tumorigenesis and also support the idea that additional co-factors or posttranslational modifications (e.g., phosphorylation) may govern the repressive or inducing role of LHX2 in tissues or cells.

Since LHX2 is a transcriptional factor, we explored the molecular mechanisms underlying its anticancer effects in the liver using RNA-seq. By interrogating the data on signaling pathways, molecular functions, and disease states, we found that LHX2 is directly connected not only to cell movement, growth, survival, and proliferation but also to lipid metabolism, molecule transportation, and cell-tocell interactions. Pathways associated with cancer and hepatic disease are also strongly altered by LHX2. Finally,
12

Liver Cancer

DOI: $10.1159 / 000521595$
Mosca et al. 
Fig. 7. Regulation of MAPK/ERK and Wnt signals by LHX2 in hepatoma cells. LHX2 inhibits ERK and Wnt pathways by inducing expression of phosphatases DUSP5/6 (in blue) and Wnt inhibitors TLE2/4 and ICAT/CTNNBIP1 (in purple), respectively. This results in ERK1/2 dephosphorylation and beta-catenin/TCF4/TCF7L2 transcriptional complex dissociation, and finally in tumor regression. TF, transcriptional factor.

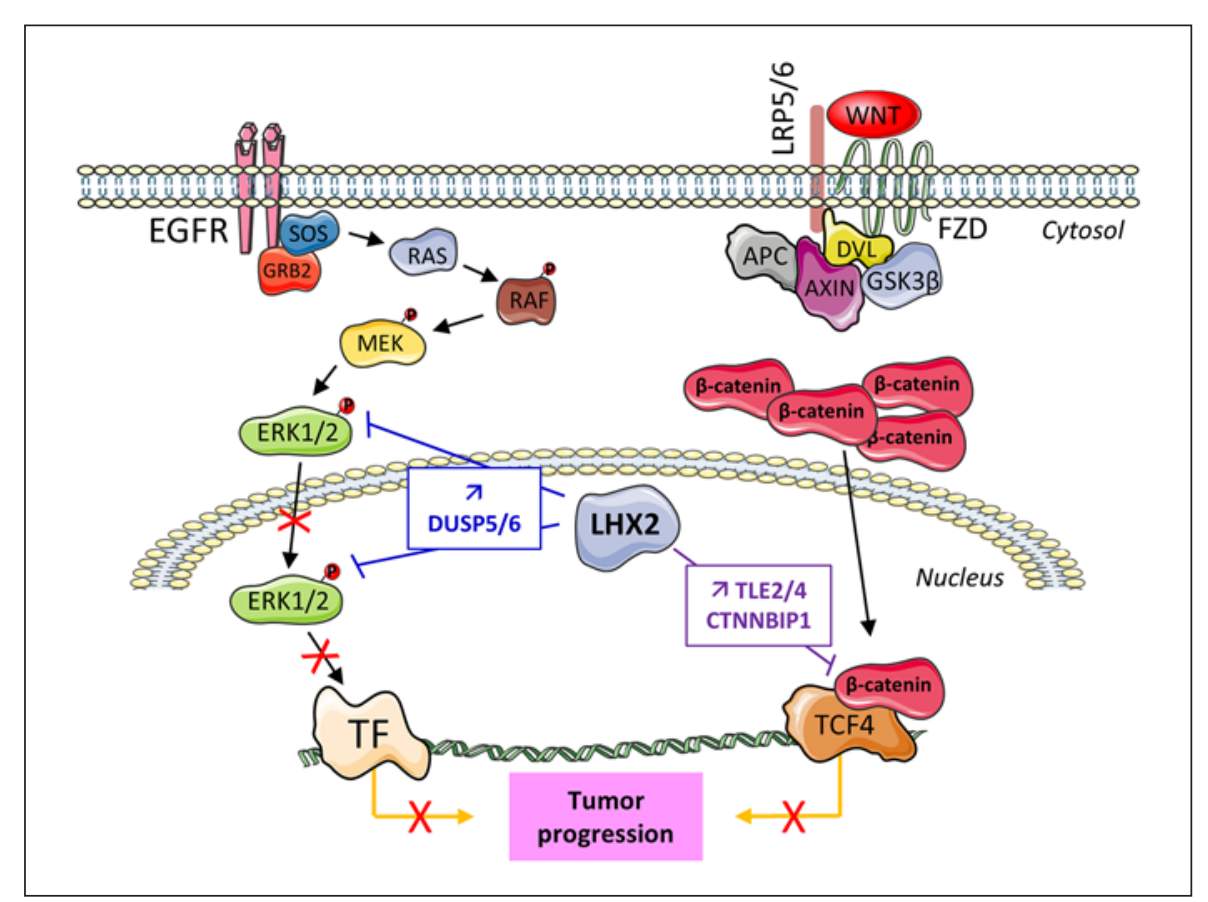

genes involved in nuclear beta-catenin/TCF/LEF transcriptional complex repression such as the CTNNBIP1/ ICAT, TCF7L1, TLE/Groucho family members (e.g., TLE2/4/6), and DACT2 were also enriched in LHX2-expressing Huh7 and HepG2 cells (Fig. 6c; online suppl. Fig. S21). For instance, ICAT is known to block the formation of the beta-catenin/TCF/LEF transcriptional complex and is involved in embryonic development and carcinogenesis [45]. The Groucho/TLE family members are master regulators in Drosophila development because of their capacity to regulate multiple signaling pathways and their key roles in many cell fate mechanisms including Wnt signaling [46, 47]. In our study, we found that LHX2 acts through a dual mechanism by inducing the expression of various secreted (e.g., DKK1), cytoplasmic (e.g., ANKRD6 and DCDC2), and nuclear (e.g., ICAT, TCF7L1, and Groucho/ TLE) Wnt inhibitors and by preventing the assembly of the beta-catenin/TCF/LEF transcriptional complex (Fig. 7). Intriguingly, LHX2-mediated Wnt inhibition was very efficient in Huh7 and HepG2 cells but not in Huh6 cells. While our findings provide some explanations for these differences, they require further investigation.

Collectively, our findings suggest that LHX2 regulates key cancer pathways in adult and pediatric liver cancers. The decrease in LHX2 observed in most HCC and in HB strongly suggests its antitumor role in liver cancer and partly explains the increased activation of the oncogenic MAPK/ERK and Wnt pathways. The future use of LHX2 agonists, the manipulation of LHX2 expression, and the identification of its targets may pave the way for potential therapeutic interventions to block the development of liver cancer in adult and pediatric patients.

\section{Acknowledgments}

We thank Laurent Journot and Hugues Parinello from the MGX-Montpellier GenomiX platform and Véronique Guyonnet from the Vectorologie platform, a service unit of the TBM Core and University of Bordeaux. The scanning and microscopy of tissue sections were done in the Bordeaux Imaging Center, a service unit of the CNRS-INSERM and University of Bordeaux, and a member of the national infrastructure France BioImaging. We thank Thierry Leste-Lasserre and Antonin Marchais for performing experiments and bioinformatic analyses not included in this paper. We also thank Jean Ripoche and Véronique Trézéguet for their kind advice and critical reading of the manuscript.

\section{Statement of Ethics}

All patients were recruited in accordance with the European and French law and institutional ethical guidelines. Samples were obtained from the Centre de Ressources Biologiques (CRB)-ParisSud (BRIF NºB-0033-00089) with written informed consent, and the study protocol was approved by the French Government and the ethics committees of HEPATOBIO (HEPATOBIO project: CPP No. CO-15-003; CNIL No. 915640). Analyses in chick and Xenopus embryos do not require ethics approval as they are performed during the very first step of embryo development. 


\section{Conflict of Interest Statement}

The authors declare no conflicts of interest.

\section{Funding Sources}

This study was supported by grants to N.M., F.Z.K., and C.F.G. from the French State in the framework of the "Investments for the future" Programme IdEx Bordeaux (Grant ANR-10-IDEX-03-02), the Fondation Groupama pour la Santé, Groupama Centre-Atlantique, la Ligue Nationale contre le Cancer, and the Région Nouvelle-Aquitaine (No. 2018-1R30114). N.M., C.F.G., and MIRCADE team also received donations from the following charities: Aidons Marina, E.S.CA.P.E., Eva pour la Vie, Les Récoltes de l'Espoir, and Sphères. Montpellier GenomiX acknowledges financial support from the France Génomique National program, funded as part of the "Investissement d'Avenir" program managed by the Agence Nationale pour la Recherche (contract ANR-10-INBS-09). The teams of J.Z.-R. and C.F.G. were funded by the National du Cancer (INCa) in the framework of the PELICAN.resist projects $\left(\mathrm{N}^{\circ} 2020-012\right)$. The team of J.Z.-R. was also funded by SFCE, Etoile de Martin, FES, Hubert, INSERM with the HTE (Cancer plan), Ligue Nationale contre le Cancer (Equipe Labellisée), Labex OncoImmunology (investissement d'avenir), the IREB grant, Coup d'Elan de la Fondation Bettencourt-Schueller, the SIRIC CARPEM, FRM Rosen award, Ligue Contre le Cancer Comité de Paris (René et André Duquesne award), and Fondation Mérieux. S.C. received funding from Labex OncoImunology and CARPEM. J.C.-R. was funded by the Catalan Agency for the Man- agement of University and Research Grants (AGAUR, 2019 FI B01024). C.A. received funding from Instituto de Salud Carlos III (PI10/02082, PI13/02340), the European Union's Horizon 2020 research and innovation program under grant agreement No. 668596 (ChiLTERN), CIBERehd (CB06/04/0033), AGAUR (2017SGR-490), and the Ramón y Cajal (RYC-2010-07249) program of the Spanish Ministry of Science and Innovation.

\section{Author Contributions}

N.M., F.Z.K., P.V., and C.F.G. performed the molecular and cellular analyses. C.A., C.M., and C.G. provided the biological samples and their associated clinical data. C.M., C.G., and C.F.G. performed the histopathological analyses. S.F. and P.T. performed the analyses in the Xenopus embryo. N.M., F.Z.K. and N.D.-S. performed the cellular and histological analyses in the chick embryo. N.M., F.Z.K., J.C.-R., A.D.R.-A., S.C., and E.D. performed the bioinformatics and comparative analyses. C.F.G., P.V., P.T., J.Z.-R., and C.A. supervised the work. C.F.G., J.Z.-R., and C.A. obtained the financial grants. N.M. and C.F.G. conceived the project and wrote the manuscript.

\section{Data Availability Statement}

All data generated or analyzed during this study are included in this article and its online supplementary material. Further enquiries can be directed to the corresponding author.

\section{References}

1 Llovet JM, Zucman-Rossi J, Pikarsky E, Sangro B, Schwartz M, Sherman M, et al. Hepatocellular carcinoma. Nat Rev Dis Primers. 2016;2:16018.

2 von Schweinitz D. Hepatoblastoma: recent developments in research and treatment. Semin Pediatr Surg. 2012;21:21-30.

3 Buendia MA. Unravelling the genetics of hepatoblastoma: few mutations, what else? J Hepatol. 2014;61:1202-4.

4 Ghousein A, Mosca N, Cartier F, Charpentier J, Dupuy JW, Raymond AA, et al. miR-4510 blocks hepatocellular carcinoma development through RAF1 targeting and RAS/RAF/ MEK/ERK signalling inactivation. Liver Int. 2020;40:240-51.

5 Eichenmuller M, Trippel F, Kreuder M, Beck A, Schwarzmayr T, Haberle B, et al. The genomic landscape of hepatoblastoma and their progenies with HCC-like features. J Hepatol. 2014;61:1312-20.

6 Malarkey DE, Hoenerhoff M, Maronpot RR. Carcinogenesis: mechanisms and manifestations. In: Haschek and Rousseaux's handbook of toxicologic pathology. 3rd ed. Cambridge: Academic Press; 2013. p. 107-46.

7 Hooks KB, Audoux J, Fazli H, Lesjean S, Ernault T, Dugot-Senant N, et al. New insights into diagnosis and therapeutic options for proliferative hepatoblastoma. Hepatology. 2018;68:89-102.

8 Rebouissou S, Franconi A, Calderaro J, Letouze E, Imbeaud S, Pilati C, et al. Genotype-phenotype correlation of CTNNB1 mutations reveals different ss-catenin activity associated with liver tumor progression. Hepatology. 2016;64:2047-61.

9 Boyault S, Rickman DS, de Reynies A, Balabaud C, Rebouissou S, Jeannot E, et al. Transcriptome classification of HCC is related to gene alterations and to new therapeutic targets. Hepatology. 2007;45:42-52.

10 Cairo S, Armengol C, De Reynies A, Wei Y, Thomas E, Renard CA, et al. Hepatic stem-like phenotype and interplay of Wnt/beta-catenin and Myc signaling in aggressive childhood liver cancer. Cancer Cell. 2008;14:471-84.

11 Carrillo-Reixach J, Torrens L, Simon-Coma M, Royo L, Domingo-Sabat M, Abril-Fornaguera $\mathrm{J}$, et al. Epigenetic footprint enables molecular risk stratification of hepatoblastoma with clinical implications. J Hepatol. 2020;73:328-41.

12 Wang X, He C, Hu X. LIM homeobox transcription factors, a novel subfamily which plays an important role in cancer (review). Oncol Rep. 2014;31:1975-85.

13 Nathalia E, Theardy MS, Elvira S, Rosellinny G, Liyanto AS, Utama MP, et al. Downregula- tion of tumor-suppressor gene LHX6 in cancer: a systematic review. Rom J Intern Med. 2018;56:135-42.

14 Doucet-Beaupre H, Ang SL, Levesque M. Cell fate determination, neuronal maintenance and disease state: The emerging role of transcription factors Lmxla and Lmxlb. FEBS Lett. 2015;589:3727-38.

15 Liang TS, Zheng YJ, Wang J, Zhao JY, Yang DK, Liu ZS. MicroRNA-506 inhibits tumor growth and metastasis in nasopharyngeal carcinoma through the inactivation of the Wnt/ $\beta$-catenin signaling pathway by down-regulating LHX2. J Exp Clin Cancer Res. 2019;38:97.

16 Kuzmanov A, Hopfer U, Marti P, MeyerSchaller N, Yilmaz M, Christofori G. LIM-homeobox gene 2 promotes tumor growth and metastasis by inducing autocrine and paracrine PDGF-B signaling. Mol Oncol. 2014;8: 401-16.

17 Wu HK, Minden MD. Transcriptional activation of human LIM-HOX gene hLH-2 in chronic myelogenous leukemia is due to a cisacting effect of Bcr-Abl. Biochem Biophys Res Commun. 1997;234:742-7.

18 Zhou F, Gou S, Xiong J, Wu H, Wang C, Liu T. Oncogenicity of LHX2 in pancreatic ductal adenocarcinoma. Mol Biol Rep. 2014;41: 8163-7. 
19 Shi X, Zhan L, Xiao C, Lei Z, Yang H, Wang $\mathrm{L}$, et al. miR-1238 inhibits cell proliferation by targeting LHX2 in non-small cell lung cancer. Oncotarget. 2015;6:19043-54.

20 Rauscher GH, Kresovich JK, Poulin M, Yan L, Macias V, Mahmoud AM, et al. Exploring DNA methylation changes in promoter, intragenic, and intergenic regions as early and late events in breast cancer formation. BMC Cancer. 2015;15:816.

21 Kolterud A, Wandzioch E, Carlsson L. Lhx2 is expressed in the septum transversum mesenchyme that becomes an integral part of the liver and the formation of these cells is independent of functional Lhx2. Gene Expr Patterns. 2004;4:521-8.

22 Porter FD, Drago J, Xu Y, Cheema SS, Wassif C, Huang SP, et al. Lhx2, a LIM homeobox gene, is required for eye, forebrain, and definitive erythrocyte development. Development. 1997;124:2935-44.

23 Wandzioch E, Kolterud A, Jacobsson M, Friedman SL, Carlsson L. Lhx2-/- mice develop liver fibrosis. Proc Natl Acad Sci U S A. 2004;101:16549-54.

24 Genz B, Thomas M, Putzer BM, Siatkowski M, Fuellen G, Vollmar B, et al. Adenoviral overexpression of $\mathrm{Lhx} 2$ attenuates cell viability but does not preserve the stem cell like phenotype of hepatic stellate cells. Exp Cell Res. 2014;328:429-43.

25 Hsu LC, Nam S, Cui Y, Chang CP, Wang CF, Kuo HC, et al. Lhx2 regulates the timing of beta-catenin-dependent cortical neurogenesis. Proc Natl Acad Sci U S A. 2015;112: 12199-204.

26 Zhang S, Li J, Lea R, Vleminckx K, Amaya E. Fezf2 promotes neuronal differentiation through localised activation of $\mathrm{Wnt} / \beta$-catenin signalling during forebrain development. Development. 2014;141:4794-805.

27 Coker EA, Mitsopoulos C, Tym JE, Komianou A, Kannas C, Di Micco P, et al. canSAR: update to the cancer translational research and drug discovery knowledgebase. Nucleic Acids Res. 2019;47:D917-22.

28 Indersie E, Hooks KB, Capdevielle C, Fabre M, Dugot-Senant N, Desplat A, et al. Tracking cellular and molecular changes in a species- specific manner during experimental tumor progression in vivo. Oncotarget. 2018;9: 16149-62.

29 Bayard Q, Meunier L, Peneau C, Renault V, Shinde J, Nault JC, et al. Cyclin A2/E1 activation defines a hepatocellular carcinoma subclass with a rearrangement signature of replication stress. Nat Commun. 2018;9:5235.

30 Hirsch TZ, Negulescu A, Gupta B, Caruso S, Noblet B, Couchy G, et al. BAP1 mutations define a homogeneous subgroup of hepatocellular carcinoma with fibrolamellar-like features and activated PKA. J Hepatol. 2020; 72:924-36.

31 Wang HW, Hsieh TH, Huang SY, Chau GY, Tung CY, Su CW, et al. Forfeited hepatogenesis program and increased embryonic stem cell traits in young hepatocellular carcinoma (HCC) comparing to elderly HCC. BMC Genomics. 2013;14:736.

32 Sumazin P, Chen Y, Trevino LR, Sarabia SF, Hampton OA, Patel K, et al. Genomic analysis of hepatoblastoma identifies distinct molecular and prognostic subgroups. Hepatology. 2017;65:104-21.

33 Valanejad L, Cast A, Wright M, Bissig KD, Karns R, Weirauch MT, et al. PARP1 activation increases expression of modified tumor suppressors and pathways underlying development of aggressive hepatoblastoma. Commun Biol. 2018;1:67.

34 Hiyama E. Gene expression profiling in hepatoblastoma cases of the Japanese Study Group for Pediatric Liver Tumors-2 (JPLT-2) trial. Tallinn: Science Repository OU; 2019.

35 Edgar R, Domrachev M, Lash AE. Gene expression omnibus: NCBI gene expression and hybridization array data repository. Nucleic Acids Res. 2002;30:207-10.

36 Meyers RL, Maibach R, Hiyama E, Haberle B, Krailo M, Rangaswami A, et al. Risk-stratified staging in paediatric hepatoblastoma: a unified analysis from the Children's Hepatic Tumors International Collaboration. Lancet Oncol. 2017;18:122-31.

37 Llovet JM, Villanueva A, Lachenmayer A, Finn RS. Advances in targeted therapies for hepatocellular carcinoma in the genomic era. Nat Rev Clin Oncol. 2015;12:408-24.
38 Huang CY, Tan TH. DUSPs, to MAP kinases and beyond. Cell Biosci. 2012;2:24.

39 Indersie E, Lesjean S, Hooks KB, Sagliocco F, Ernault T, Cairo S, et al. MicroRNA therapy inhibits hepatoblastoma growth in vivo by targeting beta-catenin and Wnt signaling. Hepatol Commun. 2017;1:168-83.

40 de La Coste A, Romagnolo B, Billuart P, Renard CA, Buendia MA, Soubrane O, et al. Somatic mutations of the beta-catenin gene are frequent in mouse and human hepatocellular carcinomas. Proc Natl Acad Sci U S A. 1998; 95:8847-51.

41 Miyashita K, Kitajima K, Goyama S, Kitamura T, Hara T. Overexpression of Lhx2 suppresses proliferation of human $\mathrm{T}$ cell acute lymphoblastic leukemia-derived cells, partly by reducing LMO2 protein levels. Biochem Biophys Res Commun. 2018;495: 2310-6.

42 Llovet JM, Villanueva A, Lachenmayer A, Finn RS. Advances in targeted therapies for hepatocellular carcinoma in the genomic era. Nat Rev Clin Oncol. 2015;12:408-24.

43 Eicher C, Dewerth A, Thomale J, Ellerkamp V, Hildenbrand S, Warmann SW, et al. Effect of sorafenib combined with cytostatic agents on hepatoblastoma cell lines and xenografts. Br J Cancer. 2013;108:334-41.

44 Cusimano A, Fodera D, D’Alessandro N, Lampiasi N, Azzolina A, Montalto G, et al. Potentiation of the antitumor effects of both selective cyclooxygenase- 1 and cyclooxygenase-2 inhibitors in human hepatic cancer cells by inhibition of the MEK/ERK pathway. Cancer Biol Ther. 2007;6:1461-8.

45 Zhang K, Zhu S, Liu Y, Dong X, Shi Z, Zhang A, et al. ICAT inhibits glioblastoma cell proliferation by suppressing Wnt/beta-catenin activity. Cancer Lett. 2015;357:404-11.

46 Pez F, Lopez A, Kim M, Wands JR, Caron de Fromentel C, Merle P. Wnt signaling and hepatocarcinogenesis: molecular targets for the development of innovative anticancer drugs. J Hepatol. 2013;59:1107-17.

47 Ramakrishnan AB, Sinha A, Fan VB, Cadigan KM. The Wnt transcriptional switch: TLE removal or inactivation? Bioessays. 2018;40. 